\title{
An experimental study and computational validation of waste heat recovery from a lab scale ceramic kiln using a vertical multi-pass heat pipe heat exchanger
}

Daniel Brough ${ }^{\mathrm{a}}$, Ana Mezquita ${ }^{\mathrm{b}}$, Salvador Ferrer ${ }^{\mathrm{b}}$, Carmen Segarra ${ }^{\mathrm{b}}$, Amisha Chauhan ${ }^{\mathrm{a}}$, Sulaiman Almahmoud ${ }^{c}$, Navid Khordehgah ${ }^{a}$, Lujean Ahmad ${ }^{a}$, David Middleton ${ }^{d}$, H. Isaac Sewell ${ }^{\mathrm{d}}$, Hussam Jouhara ${ }^{{ }^{*}}$

a- College of Engineering, Design and Physical Sciences, Brunel University London, Uxbridge, Middlesex, UB8 3PH, London, UK.

b- Instituto de Tecnología Cerámica, Campus Universitario Riu Sec, 12006 Castellón, Spain

c- Spirax Sarco Engineering PLC, Cheltenham, GL51 9NQ, United Kingdom

d- Altek Europe, Burley Close, Lakeside House, Chesterfield S40 2UB

*_ Corresponding Author. Email address: hussam.jouhara@brunel.ac.uk (H. Jouhara).

\begin{abstract}
The development of waste heat recovery technologies has surged as a result of climate change initiatives, which require energy intensive industries to curb their emissions and lower energy consumption. Installing heat pipe heat exchangers has proven to be a reliable and effective method of recovering waste heat due to their passive operation, superconductive properties and small footprint. This paper highlights the application of a vertical multi-pass heat pipe heat exchanger to a lab scale ceramic kiln system used to transfer heat from the kiln exhaust to water. The innovative heat pipe heat exchanger exists as a novel variable unit able to recover heat energy for a range of inlet temperatures and flow rates. The installed unit has shown a heat recovery rate of up to $63 \mathrm{~kW}$. A range of exhaust gas temperatures from $135-270^{\circ} \mathrm{C}$ were trialled at varying heat source and sink mass flow rates. The results of the experiments as well as simulation results using a model built using the software TRNSYS are given. The investigation has confirmed that the TRNSYS simulation results agree well with the experimental results. Additionally, return on investment analysis predicted 33 months payback for a theoretical full-scale unit preheating water for space heating.
\end{abstract}

Keywords: Heat Pipe Technology, Waste Heat Recovery, Heat Pipe Heat Exchanger, Ceramics Kiln, System Modelling.

\section{Nomenclature}

\section{Acronyms}

ANB

CRK

Annual Net Benefit

HPHE

Continuous Roller Kiln

LMTD

Heat Pipe Heat Exchanger

NTU

Logarithmic Mean Temperature Difference

P\&ID

Number of Transfer Units

ROI

Pipework and Instrumentation Diagram

TRNSYS

WHR

Return On Investment

TRaNsient SYstem Simulation

Waste Heat Recovery

\section{Symbols and Units}

A

Heat transfer surface area

$\mathrm{m}^{2}$ 


$\begin{array}{lll}C & \text { Correction factor } & \text { Dimensionless } \\ c_{p} & \text { Specific heat capacity } & \mathrm{J} \cdot \mathrm{kg}^{-1} \cdot \mathrm{K}^{-1} \\ \mathrm{D} & \text { Diameter } & \mathrm{m} \\ \mathrm{f} & \text { Frequency } & \mathrm{Hz} \\ h_{f c} & \text { Heat transfer coefficient of forced convection } & \mathrm{W} \cdot \mathrm{m}^{-2} \cdot \mathrm{K}^{-1} \\ k & \text { Thermal conductivity } & \mathrm{W} \cdot \mathrm{m}^{-1} \cdot \mathrm{K}^{-1} \\ \mathrm{M} & \text { Molecular weight of gas } & \mathrm{kg} \cdot \mathrm{mol}^{-1} \\ \dot{\mathrm{m}} & \text { Mass flow rate } & \mathrm{kg} \cdot \mathrm{s}^{-1} \\ \mathrm{n} & \text { Number of moles of gas } & \mathrm{mol} \\ N u_{D} & \text { Nusselt number associated with diameter of heat pipe } & \mathrm{Dimensionless} \\ \mathrm{P} & \text { Pressure } & \mathrm{Pa} \\ \mathrm{Pr} & \text { Prandtl number } & \mathrm{Dimensionless} \\ \dot{Q} & \text { Heat transfer rate } & \mathrm{J} \cdot \mathrm{s}^{-1}(\mathrm{~W}) \\ \mathrm{R} & \text { Universal gas constant } & 8.314 \mathrm{~Pa}^{3} \cdot \mathrm{mol}^{-1} \cdot \mathrm{K}^{-1} \\ R e_{D} & \text { Reynolds number associated with outer diameter of heat } \mathrm{pipe} & \mathrm{Dimensionless} \\ \mathrm{S}_{\mathrm{x}} & \text { Associated uncertainty of variable } \mathrm{x} & \mathrm{Dimension} \mathrm{of} \mathrm{x} \\ \mathrm{T} & \text { Absolute temperature } & \mathrm{K} \\ \mathrm{U} & \text { Overall heat transfer coefficient } & \mathrm{W} \cdot \mathrm{m}^{-2} \cdot \mathrm{K}^{-1} \\ U_{\max } & \text { Maximum velocity times free-flow velocity } & \mathrm{m} \cdot \mathrm{s}^{-1} \\ \dot{V} & \text { Volumetric flow } & \mathrm{m} \cdot \mathrm{s}^{-1}\end{array}$

\section{Greek symbols}

\section{$\Delta$}

$\varepsilon$

$v$
Difference

Effectiveness

Kinematic velocity
Dimensionless

Dimensionless $\mathrm{m}^{2} \cdot \mathrm{s}^{-1}$

\section{Subscripts and superscripts}

$\begin{array}{ll}\dot{m} \mathrm{w} & \text { Mass flow rate of water } \\ \mathrm{c}, \mathrm{in} & \text { Cold sink fluid inlet } \\ \mathrm{c}, \text { out } & \text { Cold sink fluid outlet } \\ \mathrm{h}, \mathrm{in} & \text { Hot source fluid inlet } \\ \mathrm{h}, \text { out } & \text { Hot source fluid outlet } \\ \mathrm{lm} & \text { Logarithmic mean } \\ \mathrm{s} & \text { Source } \\ \mathrm{sur} & \text { Surface of tube wall } \\ \mathrm{t}, \text { in } & \text { Temperature inlet } \\ \mathrm{t}, \text { out } & \text { Temperature outlet } \\ \mathrm{x} & \text { Exponent of } \operatorname{Re}_{D}\end{array}$

\section{Introduction}

Emissions released from human activities are thought to contribute to climate change. Global thought is strongly turning towards the sustainable use of natural resources. The proportion of worldwide gross domestic product from the industrial sector was 30.5\% in 2017 [1], which in turn contributed $33 \%$ of all greenhouse gas emissions [2] from $26 \%$ of primary energy consumption [3]. $\mathrm{CO}_{2}$, a greenhouse gas, has been cited as the main cause for climate change [4], with global emissions being $37.1 \mathrm{Gt}$ in 2018 [5]. Approximately, 70\% of energy consumption in industry is attributable to heating [2], therefore, there is great opportunity for utilising waste heat by recovery or reuse with energy intensive companies looking to install 
equipment to recover waste heat [6]. Industrial waste heat has been described as 'energy that is generated in industrial processes which is not put into any practical use and is wasted or dumped into the environment' [7]. The ceramic industry is an energy intensive industry [8], Mezquita et al. [9] state that $260 \mathrm{~kg}$ of $\mathrm{CO}_{2}$ is produced per tonne of fired tile, which equates to around $90 \%$ of the total $\mathrm{CO}_{2}$ emissions from the process. Ros-Dosdá et al. [10] propose that the EU's $2020 \mathrm{CO}_{2}$ emission target can be met with existing technology but the 2050 reduction targets will not be met unless further measures are addressed, 25 of which were assessed for efficacy. The authors suggest that increasing energy efficiency in thermal processes can accrue the highest reduction in $\mathrm{CO}_{2}$ equivalent emissions, up to $45 \%$. Further information regarding energy efficiency in the ceramic industry can be found in a review by Agrafiotis and Tsoutsos [11] who provide a thorough examination of the European ceramic sector with applicable energy saving technologies.

The two most energy intensive processes in the ceramic tile manufacturing process are the drying and firing stages. Of these, the firing stage is the most energy intensive with world total thermal energy consumption estimated at $1.82 \times 10^{5} \mathrm{GWh}$ [12]. A typical kiln that fires ceramic tiles is a continuous roller kiln (CRK), with 8000 currently in operation worldwide [12]. In a CRK, tiles are passed through a tunnel, that can be hundreds of meters long [13], at a constant uninterrupted speed, on rollers. There are two main sections, firstly the heating and firing zone and then a cooling zone, best summarised by Ferrer et al. [12], shown by Figure 1.

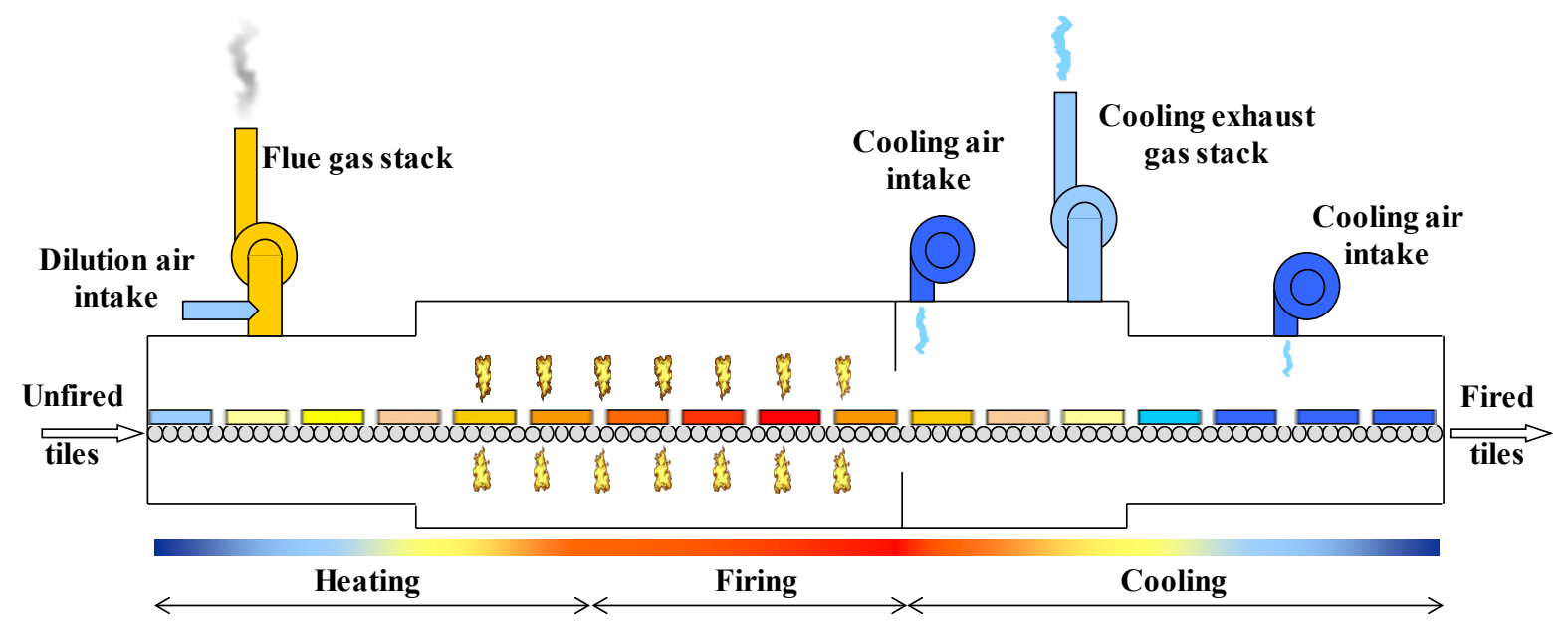

Figure 1: Diagram of a Continuous Roller Kiln, reproduced from [12].

Combustion burners, predominantly using natural gas, provide the heat energy in order to fire the tiles to form the final product. The combustion exhaust gases are directed away from the kiln via a flue, which is located near the entrance. Once the tiles reach their highest temperature within the peak temperature zone, ambient air is then blown onto the tiles to in order to cool them by removing the heat. The resulting hot gases from this section are directed through a separate stack known as the cooling flue towards the exit of the kiln. Both the cooling gases and the combustion gases can be targeted with waste heat recovery (WHR) technology. Exhaust gas from combustion and cooling gases stacks are responsible for 50-60\% of energy losses, as shown by Figure 2. Only 3\% of the energy is directed to the fired tiles. 


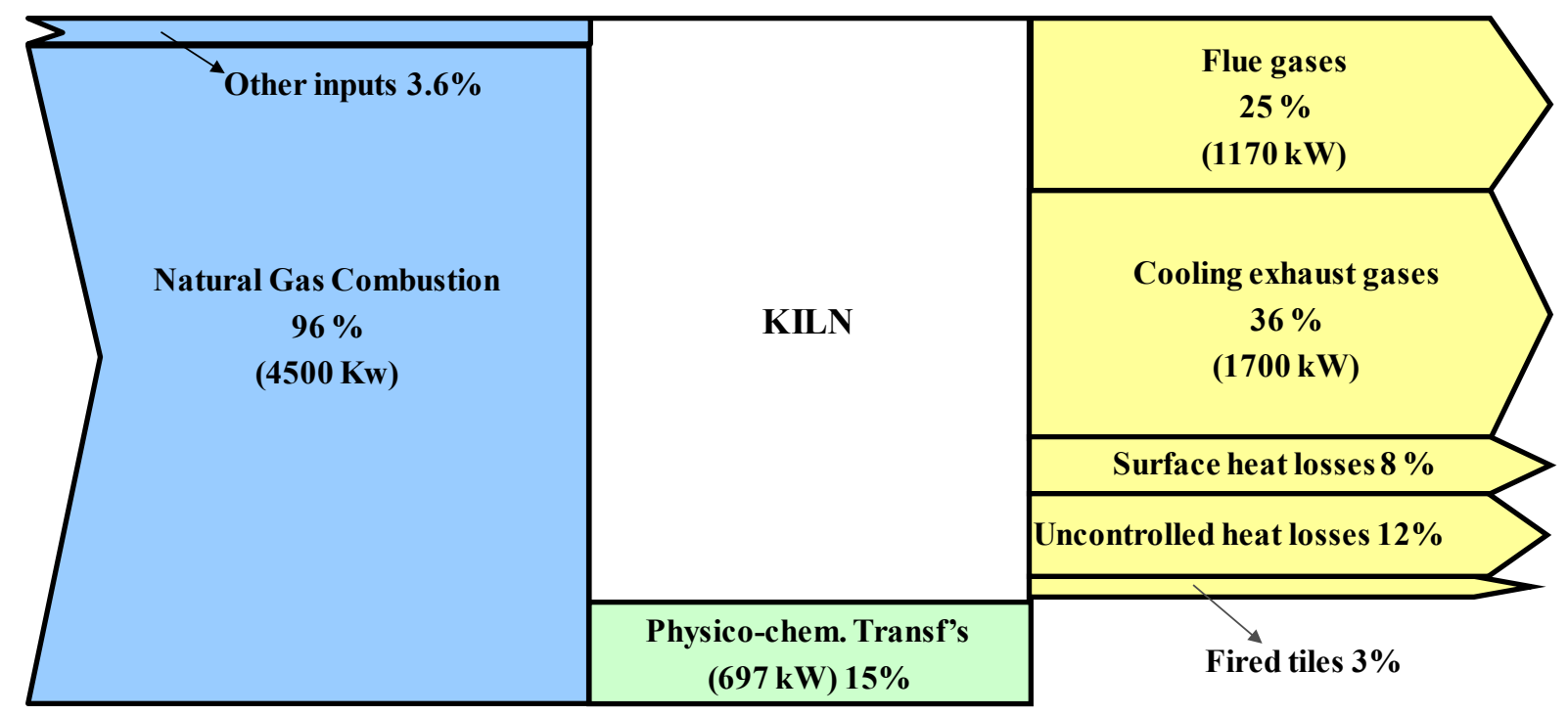

Figure 2: Sankey Diagram of a typical roller kiln, reproduced from [12].

Exhaust gases within the ceramic industry remain as one of the most lucrative opportunities for WHR, with many applicable technologies available. The failure of traditional technologies is due to the chemical composition and particulate loading of the exhaust gases from intensive process industries. Acidic gases that form a proportion of the composition of the exhaust gases can condense if temperatures drop below their dew point in cold spots, that can lead to significant corrosion. The presence of particulates can lead to fouling; the build-up of material on heat transfer surfaces within the heat exchanger leads to reduced performance. These issues can be counteracted by using a heat exchanger composed of heat pipes; a Heat Pipe Heat Exchanger (HPHE). As heat pipes operate isothermally, cold spots are avoided and corrosive material does not condense by dropping below their dew point. The smooth internal profile and low pressure drop across the heat exchanger contribute to reducing the rate of fouling.

The application of heat pipes is a prominent area of research and is a highly desirable technology for multiple industries ranging from steelworks [14] to cryogenics [15]. The technology consists of a hermetically sealed pipe containing a small quantity of working fluid, which is split into evaporator, condenser and adiabatic sections. When the evaporator section is placed within a hot stream, the working fluid will boil. The vapour formed travels through the pipe to the condenser section, which is located in a cooler stream. The vapour releases its latent heat, the vapour condenses back into a liquid, which returns to the evaporator by gravity or internal wicks. A heat pipe that is gravity-assisted without an internal wick is known as a thermosyphon or wickless heat pipe. The heat exchanger in this study was a thermosyphonequipped heat exchanger but these are commonly known as heat pipe heat exchangers. A wick is used so that capillary action can return the working fluid to the evaporator, typically wicks are used in anti-gravity applications. The two-phase process described above is a key feature of the heat pipe allowing for a completely passive and continuous operation [16], as shown by Figure 3. 


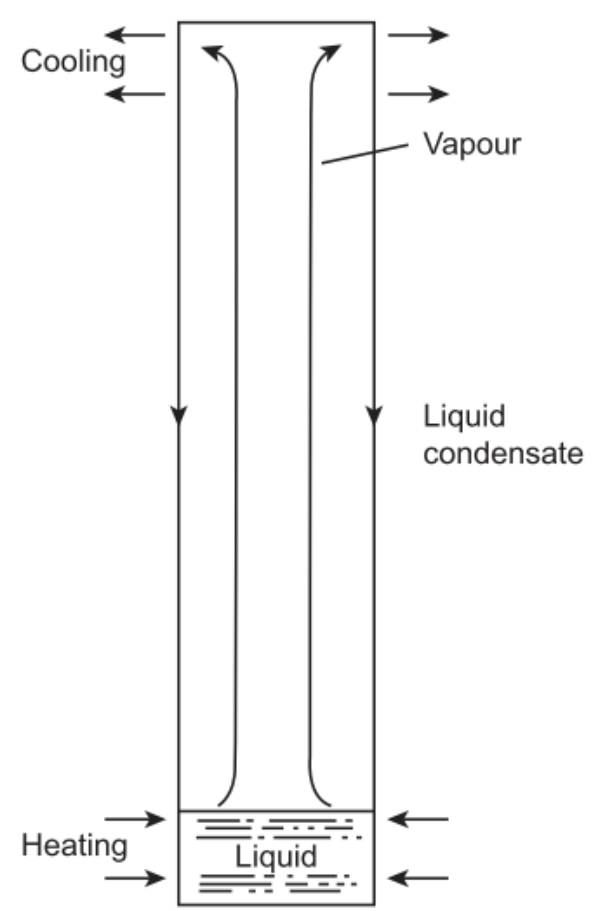

(A)

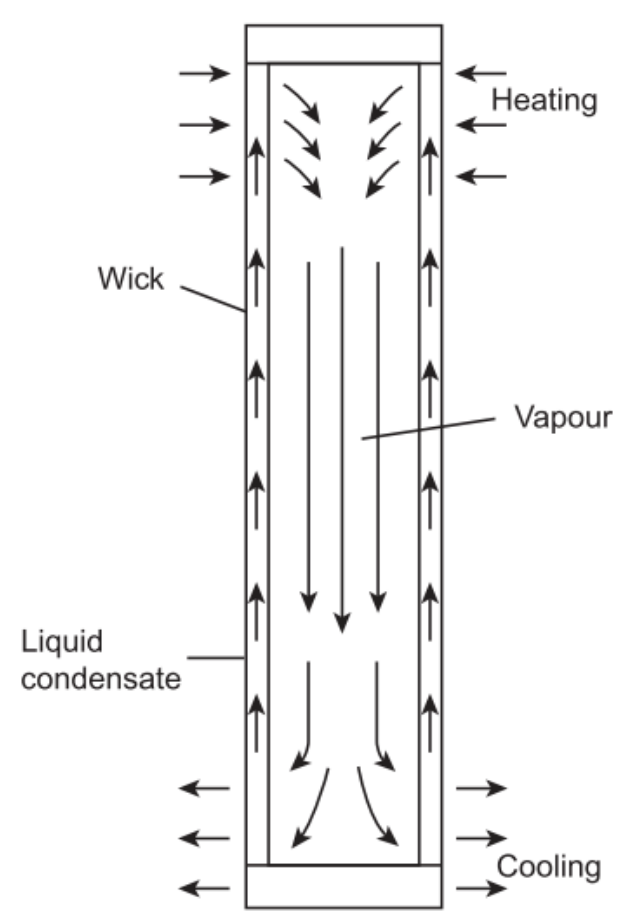

(B)

Figure 3: The typical structures of a thermosyphon (A) and heat pipe (B). Reproduced from [17].

An array of individual heat pipes is used in a HPHE. The configuration of the heat pipes in a HPHE can be organised in a staggered or in-line arrangement. Over time, HPHEs have been developed to optimise heat recovery by introducing internal baffles into the design to create multiple passes of the heat source or heat sink fluid. The addition of passes within a system has been utilised in a number of heat exchangers such as shell and tube structures [16] and theoretically will increase the overall energy recovery of an already effective system with minimal maintenance. Heat pipes are commonly studied in regard to WHR applications. Studies have been conducted on working fluid fill ratios [18] and the effects of the inclination angle of the heat pipe [19]. The studies around key variables offer an insight into the variation in thermal performance and the identification of potential uses. CFD simulations around heat pipes has been heavily focused around simulating the difficult multiphase process within the heat pipe [20] and the applicability of heat pipes within different industries but the effect of passes has not been thoroughly investigated. Pivotal points within the simulation of heat pipes was the successful modelling of geyser boiling and the multiphase process by Jouhara et al. [21] and Fadhl et al. [22], respectively.

The advances in heat pipe research has aided progression in multiphase modelling, allowing the study of key variables that directly influence the performance of heat pipes. The simulations around singular heat pipes are vast, but simulations based around HPHEs are scarce. The installation of HPHEs in practical and industrial applications is steadily increasing [23], which will be aided by the utilisation of simulation techniques. The effects studied in single pipe models largely influence the heat pipe configuration and composition. Studies investigating fill ratios with regard to preventing dry out, a phenomenon where all the working fluid is in vapour phase, can heavily influence larger scale systems, with the fill ratio and possibility of dry out heavily affecting the thermal performance of the system. Even though these variables directly influence the performance of a HPHE, the number of published simulations does not reflect this. External influences need to be considered with HPHEs, such as flow direction and number 
of passes. The effect of passes has been widely studied but has been simulated in selected HPHE studies. Ramos et al. [24] investigated the effects of a single pass air to water cross-flow HPHE. The simulation is based on the previous experiments conducted by Mroue et al. $[25,26]$ based on a three-pass HPHE. Both systems were simulated under steady state profiles with comparable assumptions. Both simulations highlight the improved thermal performance by introducing multiple passes. This paper aims to build upon this research by experimentally characterising a multi-pass HPHE installed for an industrial application.

The application of HPHE technology within the ceramic industry has recently been investigated. Delpech et al. [27] investigated the potential of HPHE technology by analysing the energy efficiency within the ceramic industry. The paper highlights the potential emission and fuel reduction if implemented across the ceramic industry. The study involved the development of a full scale HPHE suitable for the ceramic industry, though this HPHE was not a multipass unit and was an exhaust to air unit taking exhaust gas from cooling stack. A further paper by, Delpech et al. [28] investigated a novel heat pipe design to assist in the cooling of ceramic tiles. The developed heat pipe was designed to transfer energy via radiation, which can be used to cool down tiles and minimise the thermal stress within the tiles during the cooling process. The operation of the radiative panel highlighted an innovative application to cool and optimise manufacturing systems. The potential for heat pipe-based WHR systems is vast within the ceramic industry with multiple streams for waste heat recovery identified $[9,23]$.

The following paper outlines the experimental and simulated results of a novel multi-pass vertical HPHE system implemented at the exhaust of a lab scale ceramic kiln. This particular system was designed as a variable unit to allow the HPHE to operate effectively at a range of set points and operational conditions. The objective of the study was to demonstrate technical and economic feasibility of a multipass HPHE applied to variable and industrially available waste heat recovery scenarios. Review of available literature shows a lack of existing TRNSYS models specifically for WHR using a HPHE of this configuration in a lab scale system using real experimental data. The theoretical knowledge gained by assessing multiple conditions over a period of time in a quasi-transient manner will aid the design, validation and further implentation of these type of heat exchangers where other traditional technologies are not viable. The use of the dedicated system simulation software TRNSYS will aid the design of the HPHEs applied to challenging waste heat streams that are not steady state and aid with performance prediction when installing systems for real world applications. The structure of this paper is split into the following sections, Methodology, Results, Discussion and Analysis of Results and Conclusion. The Methodology section provides details on how the experiment, simulation and return on investment study was conducted, the Results section provides the outcomes obtained from the studies. Further analysis of the results is given in the Discussion and Analysis of Results section. The main findings are summarised in the Conclusion with reccomendations for future work.

\section{Methodology}

\subsection{Experimental Setup}

A HPHE has been installed at the pilot plant of the Instituto de Tecnología Cerámica (Institute of Ceramic Technology- ITC) in Castellón, Spain, to study its energy recovery performance at a temperature range up to $270^{\circ} \mathrm{C}$ from exhaust gases of a lab scale kiln with the heat sink being water. The multi-pass HPHE in this study has three passes of the exhaust gas. It is equipped with 100 of $28 \mathrm{~mm}$ outer diameter thermosyphons in a 10x10 staggered arrangement, $1518 \mathrm{~mm}$ in length. The evaporator section of the heat pipe was $1210 \mathrm{~mm}$ in length, the condenser section 
$250 \mathrm{~mm}$ in length with the internal working fluid being distilled water. The kiln is a roller kiln, fitted with 8 natural gas burners. The oxidizing agent used for combustion is ambient air, and there is a centrifugal fan to introduce the air to the burners with roughly $20 \%$ excess air. The outlet of the combustion gases through the stack is generated by convection from a pressure differential. The control panel of the kiln allows operators to regulate the heating or cooling rate and the cycle time. A set point temperature can be fixed and automatically controlled from $100^{\circ} \mathrm{C}$ up to $1200^{\circ} \mathrm{C}$. The design of the HPHE did not allow for recovery from higher temperatures due to the working fluid selection. Other working fluids and material selection can be used to recover energy from a higher temperature range. Figures 4 and 5 shows a general view and schematic of the pilot kiln located at the ITC facilities. The HPHE installed is shown in Figure 6.

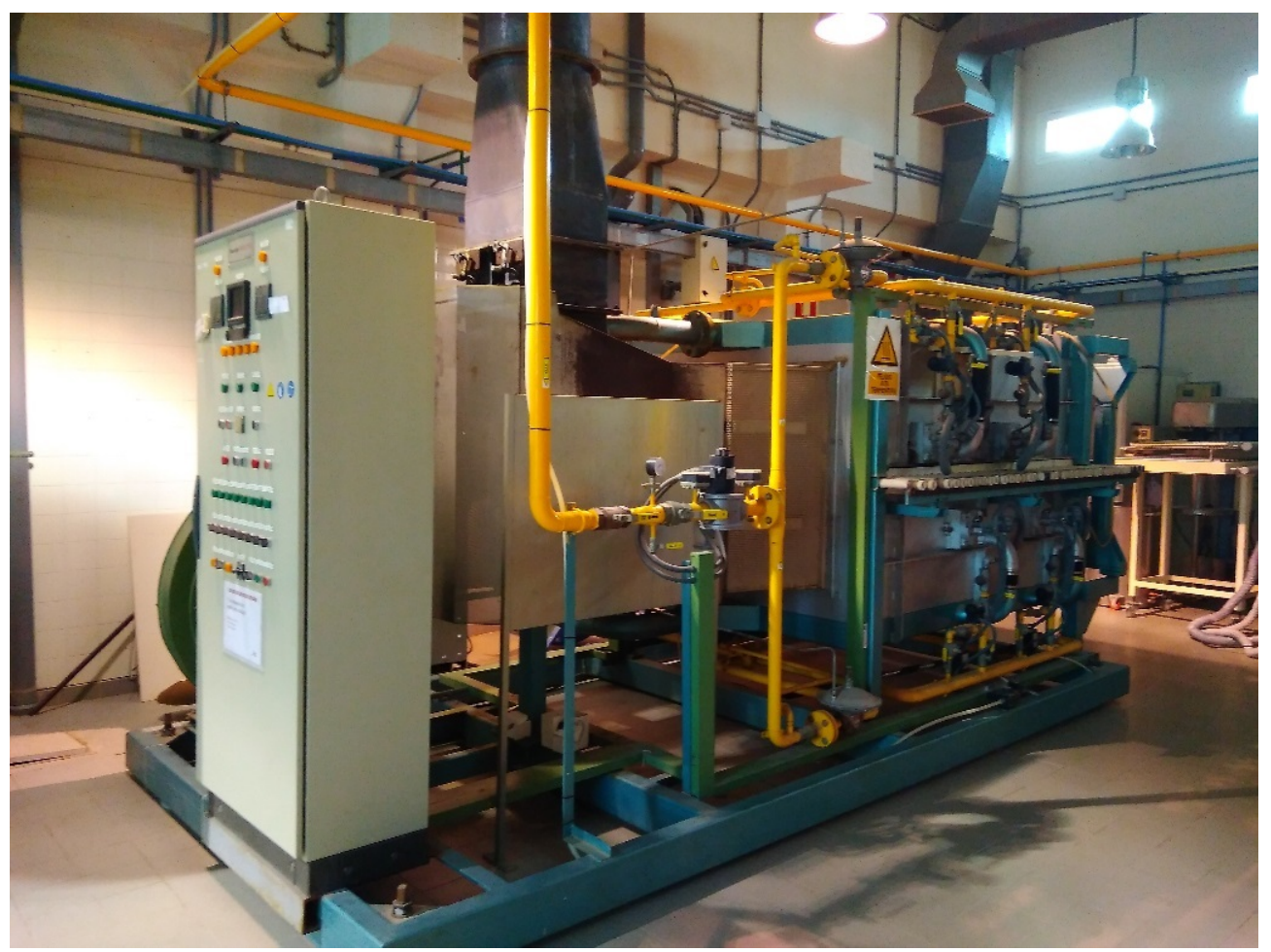

Figure 4: Pilot kiln located at ITC facilities, prior to the installation of the HPHE system. 


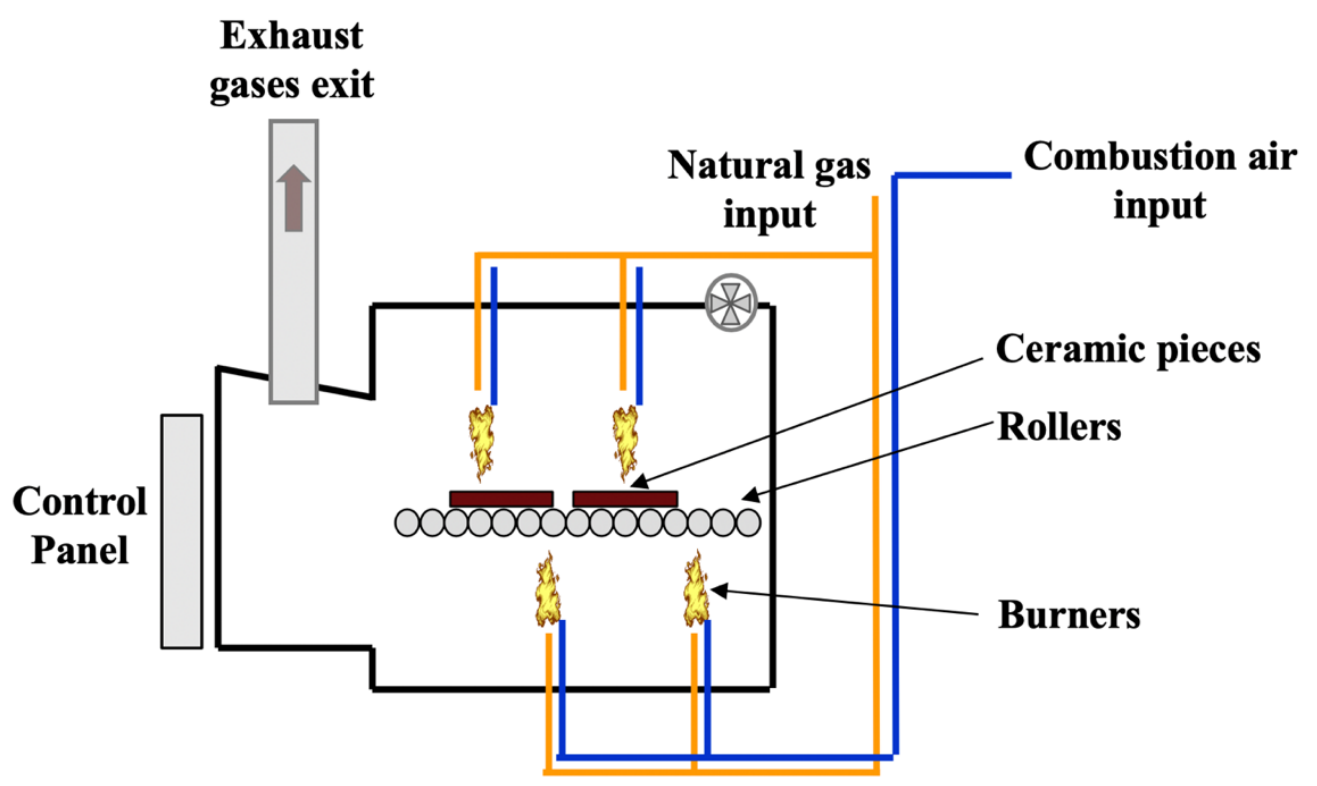

Figure 5: Schematic of pilot kiln.

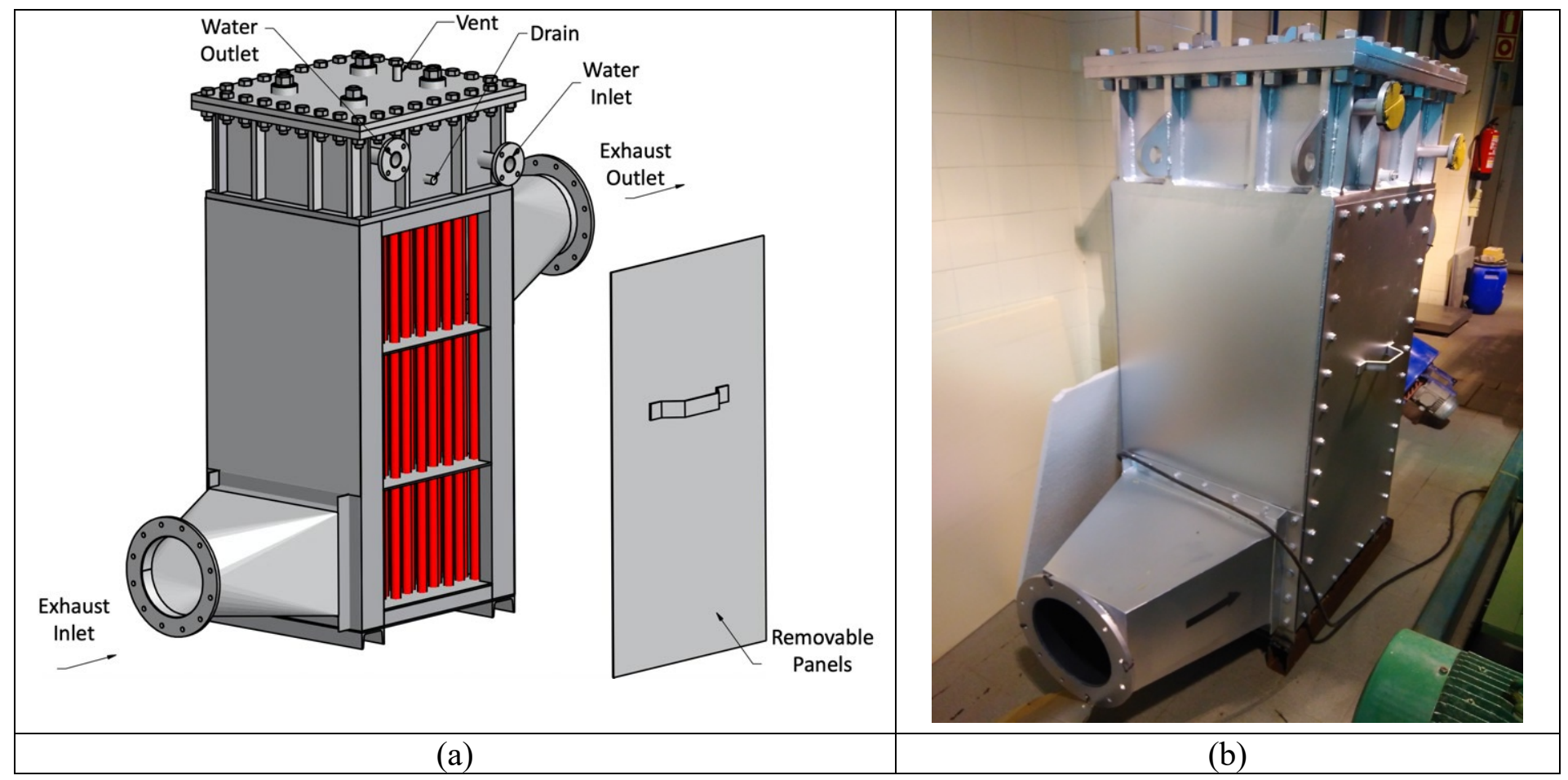

Figure 6: (a) 3D model of the HPHE. (b) HPHE in situ.

The composition of the stack exhaust gases at the pilot kiln were tested in order to obtain valid $c_{p}$ values. The following were identified:

- Nitrogen and Oxygen (combustion gas analyser Testo 350 XL), coming from excess air used in the burners for the combustion process and from the parasitic air that enters the kiln.

- Carbon dioxide and water vapour, predominantly coming from the natural gas combustion and parasitic air. 
In this pilot kiln, no other major relevant gases are found. There are negligible acidic compound precursors present (those containing sulphur, chloride and fluorine) that usually come from the ceramic product that is being fired in industrial kilns. Due to the possibility of setting different working temperatures, the pilot kiln is appropriate when studying the performance of the HPHE under different working conditions. In addition to this, it is possible to inject water and other materials to change the composition of the exhaust gas and introduce artificial fouling for additional future studies.

Although the kiln has up to eight burners to reach the desired temperatures, it was only necessary to have two firing. The HPHE was connected to the stack of the kiln. Since the outlet of the exhaust gases from the kiln is generated by convection, a fan was installed to force the gases to pass through the HPHE and return them to the stack after the heat exchanger, where they are released into the atmosphere. Figure 7 shows a P\&ID diagram of the experimental installation. A solenoid valve was installed to isolate the HPHE from the exhaust gases when not operational. Figure 8 shows the final installation of the HPHE with connections to the kiln. Knowledge of the results of the tests carried out will be crucial, before its deployment in a specific industrial site, in particular, the performance of this heat recovery system under several real working conditions.

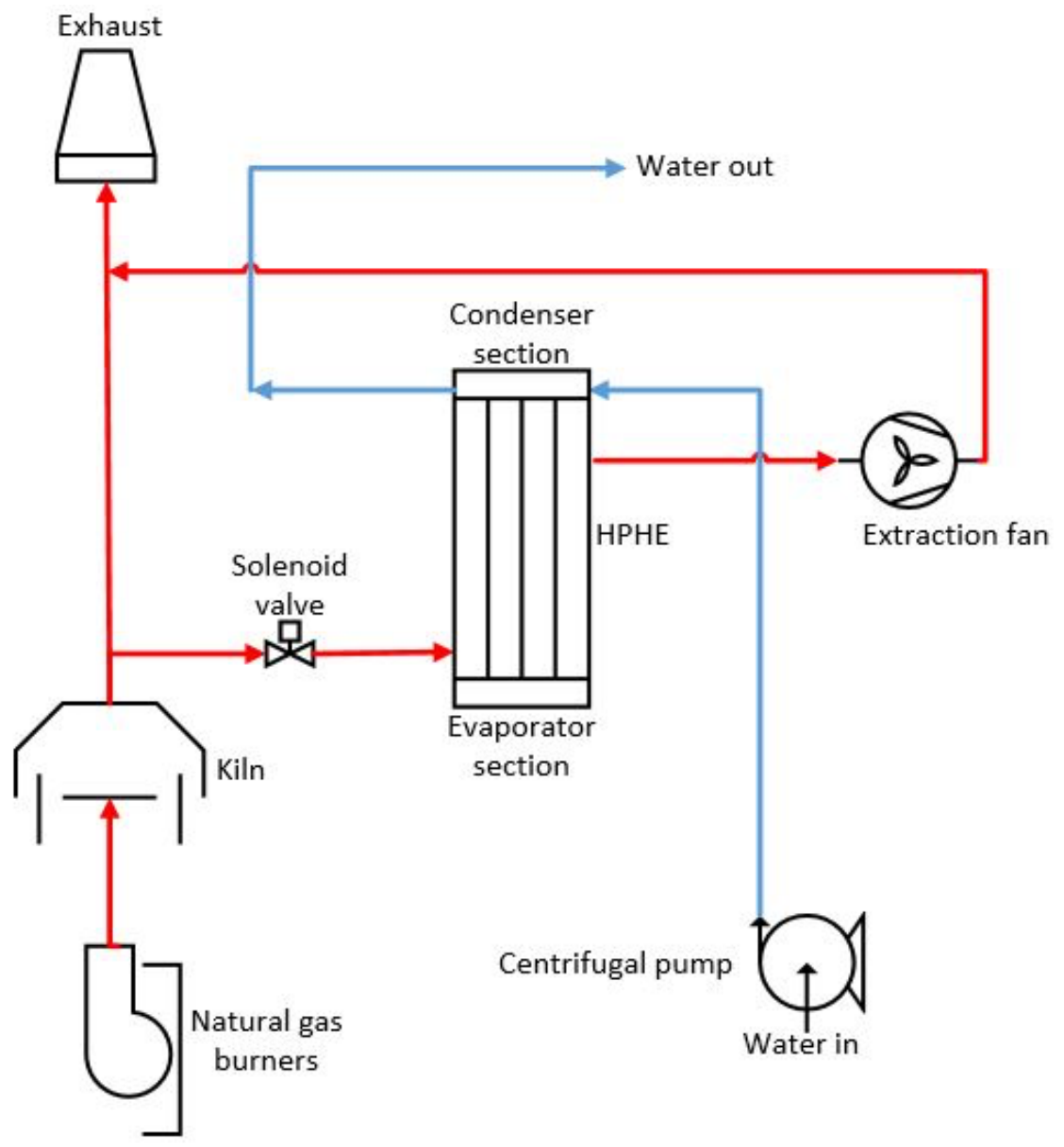

Figure 7: P\&ID Diagram of the Experimental Installation. 

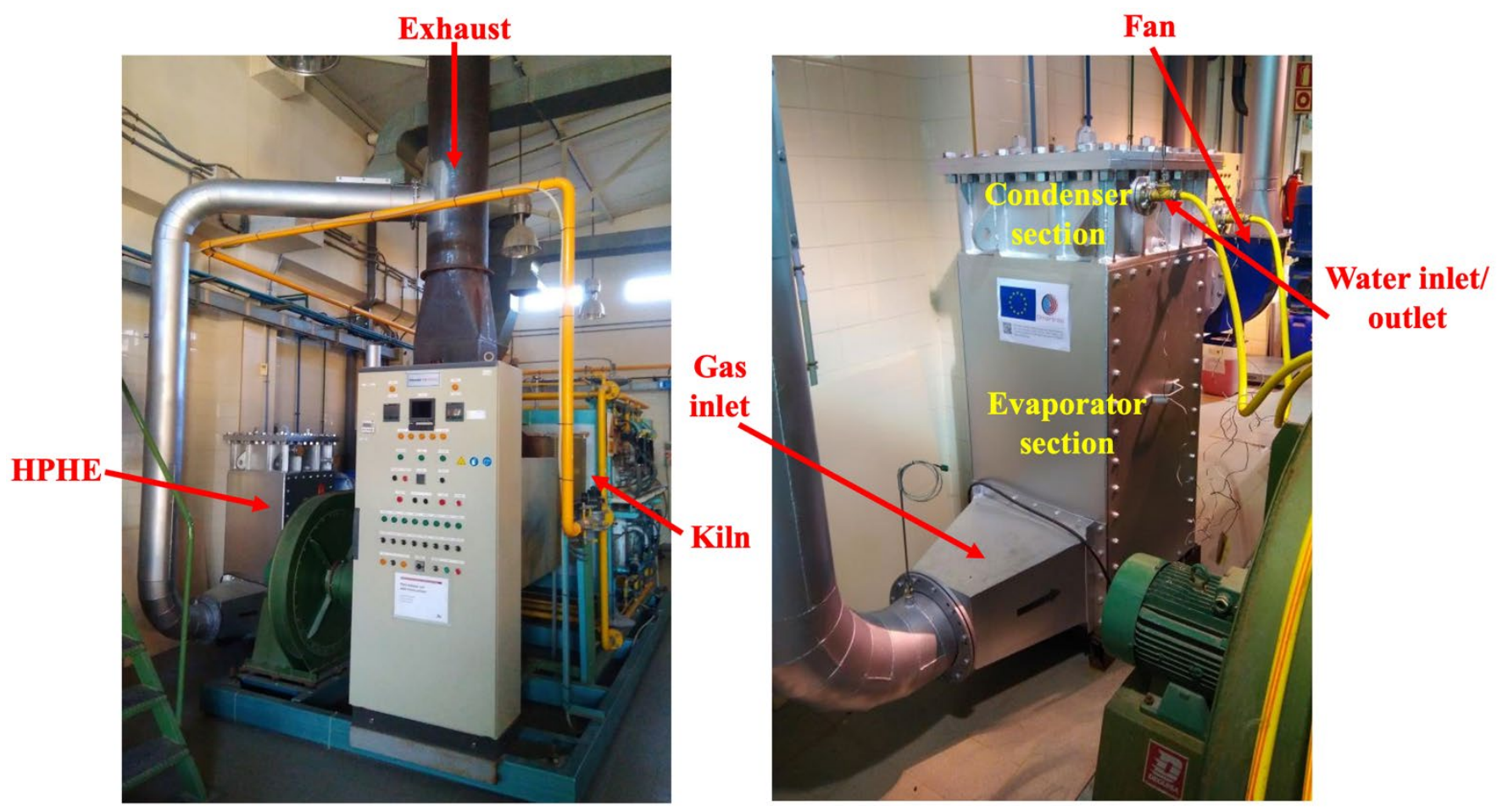

Figure 8: Installed HPHE system.

Sensors were installed to measure condition parameters when carrying out the tests. In addition to that, an inverter was incorporated to control the fan used to move the exhaust gases through the HPHE to modify the volume flow rate of gases. The parameters measured, the sensors installed and their location in the system are listed in Table 1.

Table 1: Measured parameters, sensors installed and location.

\begin{tabular}{|c|c|c|c|}
\hline Parameter & Sensor & Location & Uncertainty \\
\hline \multirow{2}{*}{$\begin{array}{c}\text { Temperature of exhaust } \\
\text { gases }\end{array}$} & \multirow{2}{*}{ Thermocouple type $\mathrm{K}$} & Inlet of HPHE & \multirow{2}{*}{$\begin{array}{c} \pm(0.15 \% \\
\left.\text { Reading }+1.1^{\circ} \mathrm{C}\right)\end{array}$} \\
\hline & & Outlet of HPHE & \\
\hline \multirow{2}{*}{$\begin{array}{l}\text { Volume flow rate of } \\
\text { exhaust gases }\end{array}$} & \multirow{2}{*}{$\begin{array}{l}\text { Pitot tube type } \mathrm{L}+ \\
\text { manometer }\end{array}$} & Inlet of HPHE & \multirow{2}{*}{$5 \%$} \\
\hline & & Outlet of HPHE & \\
\hline \multirow{2}{*}{ Temperature of the water } & \multirow{2}{*}{$\begin{array}{l}\text { P100 platinum thermistor } \\
\text { probes, } 4 \text { wires }\end{array}$} & Inlet of HPHE & \multirow{2}{*}{ $\pm 1^{\circ} \mathrm{C}$} \\
\hline & & Outlet of HPHE & \\
\hline $\begin{array}{l}\text { Volume flow rate of } \\
\text { water }\end{array}$ & Rotameter & Inlet of HPHE & $2 \%$ \\
\hline
\end{tabular}

The data measured by the sensors of temperature are registered by using an Omega data logger (model OM-DAQXL); the volume flow rates of exhaust gases and water are measured and checked discontinuously once the system is working in steady state conditions, in each of the conditions studied.

Five experiments were conducted with varying temperatures, exhaust mass flow rates altered by the fan and water mass flow rates to alter the condenser flow rate. Table 2 shows a summary of the experiments conducted. 
Table 2: Summary of experiments

\begin{tabular}{|c|c|c|c|}
\hline Experiment & $\begin{array}{c}\text { Exhaust Temperature Aim, } \\
{ }^{\circ} \mathrm{C}\end{array}$ & $\begin{array}{l}\text { Water flow rate, } \\
\text { kg.hr-1 }\end{array}$ & $\begin{array}{c}\text { Fan Speeds tested, } \\
\mathrm{Hz}\end{array}$ \\
\hline 1 & 135 & 480 & $\begin{array}{c}25,30,35,40,45 \\
50\end{array}$ \\
\hline 2 & 230 & 480 & $\begin{array}{c}25,30,35,40,45 \\
50\end{array}$ \\
\hline 3 & 230 & 1320 & $25,35,50$ \\
\hline 4 & 265 & 480 & $25,30,35,40,45$ \\
\hline 5 & 265 & 1320 & $25,35,45,50$ \\
\hline
\end{tabular}

\subsection{System Modelling}

Further to the experimental setup, a computational study was conducted using the simulation software TRNSYS (TRaNsient SYstem Simulation). The TRNSYS programme is a system modelling software developed by members of the Solar Energy Laboratory at the College of Engineering within the University of Wisconsin. The system was first released 35 years ago and is currently on its $18^{\text {th }}$ iteration. The software is recognised globally and highly regarded by researchers and engineers when used to study thermal systems. It is installed with a 150+ component library to heating, ventilation and air conditioning equipment with components ranging from heat exchangers to fans. TRNSYS enables a user to model a transient system, whilst analysing and evaluating the chosen and fixed input parameters. An interface is used called 'Simulation Studio' where the system to be tested is graphically modelled using components, known as 'Types', either from a library or personally developed. These components are internally composed of a series of mathematical equations where an input value is converted to an output value. The user can choose the input values and alter the parameters to provide a graphical view of a systems functionality over a set period of time. The various parameters are set within the Control Cards tab in the toolbar and within the components. The input values can be fixed or transient. A transient nature input, as in this case, can be achieved by using a data file (.txt/.csv) as an input or combining an output of one component as an input for another. For example, temperature profiles from experimental results or weather data files of particular cities found worldwide can be used.

The system has been used extensively in the areas of solar energy and heat recovery, such as modelling photovoltaic thermal systems using heat pipe technology [29] and simulating thermoelectric generators [30]. This study aims to fill an existing research gap by simulating heat recovery from a ceramics kiln exhaust using a vertical multi-pass heat pipe heat exchanger in TRNSYS. Figure 9 shows the TRNSYS model developed to model the system. A description of the components and design parameters used are found in Table 3 and Table 4, respectively. Non-SI units are presented in this paper as the data is based upon the measurement units used by the sensors in Table 1 as these measured the set point values that were aimed for during the experiment. Furthermore, these were the values input into the TRNSYS model so have been reported as such.

In the model, the aim of the HPHE was to heat water from exhaust gases, reflecting the experimental setup. A HPHE component is not currently available but considering the heat pipes as superconductors, a cross-flow heat exchanger can be used to approximate the performance. A pump provides a steady flow of water to the condenser section. It takes a water temperature profile and flow rate from the calculator. Temperature data provides the temperature profile of the gas and an extraction fan pulls the combustion air through the HPHE 
evaporator section. The inlet and outlet temperatures are all displayed graphically by the plotter, where the results were exported for further analysis.

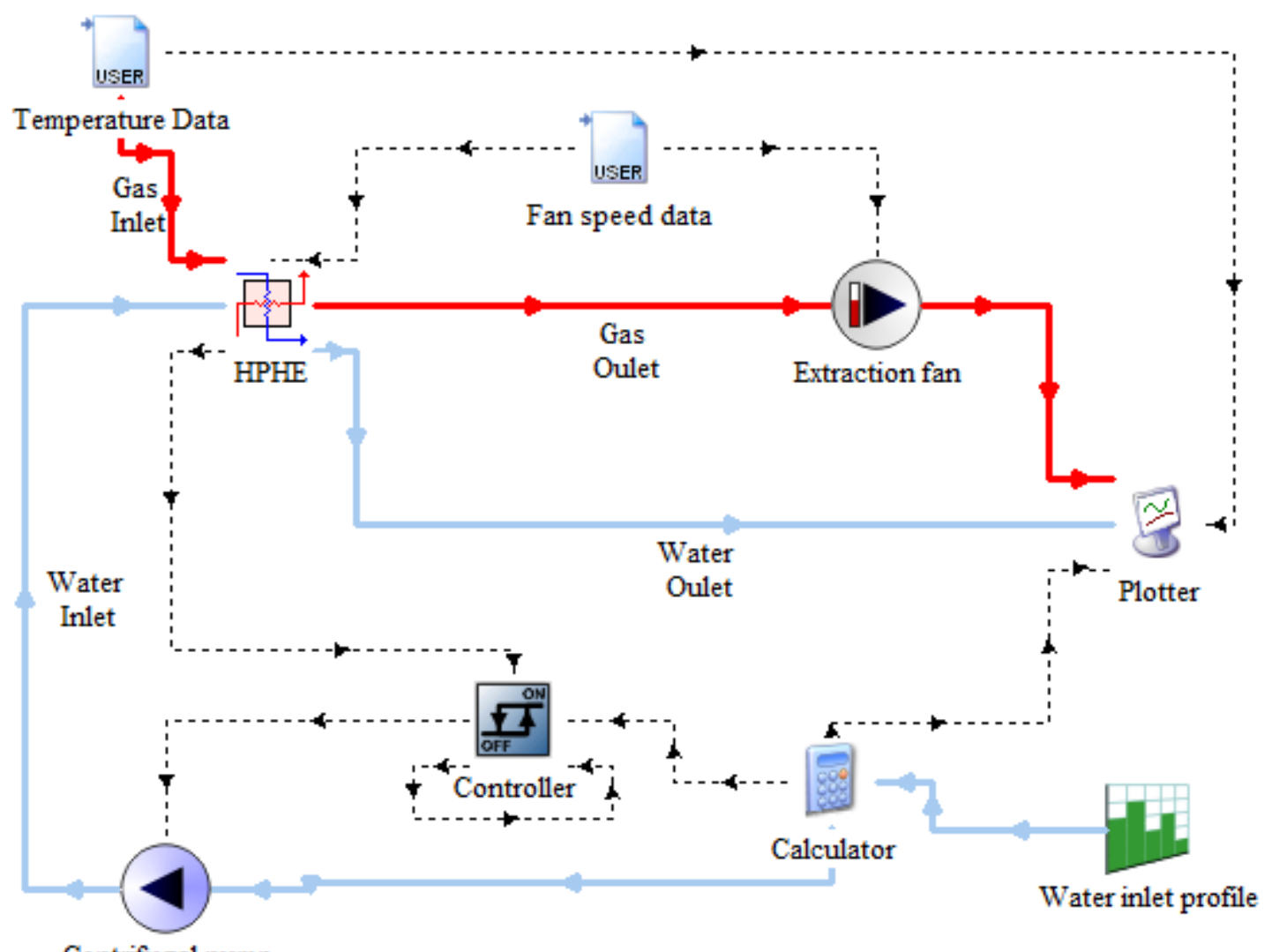

Centrifugal pump

Figure 9: The TRNSYS model developed in Simulation Studio for the system.

Table 3: The components used in the TRNSYS model and a description of their function.

\begin{tabular}{|c|c|c|}
\hline Component Name & $\begin{array}{c}\text { Corresponding Library } \\
\text { Type }\end{array}$ & Description \\
\hline $\begin{array}{c}\text { Temperature and Fan speed } \\
\text { Data }\end{array}$ & Type 9a & $\begin{array}{c}\text { Input temperature to and } \\
\text { exhaust gas flow through the } \\
\text { HPHE. }\end{array}$ \\
\hline HPHE & Type $5 \mathrm{f}$ & $\begin{array}{c}\text { Cross-flow heat exchanger. } \\
\text { Both fluids mixed. }\end{array}$ \\
\hline Extraction fan & Type 111a & Variable speed fan. \\
\hline Plotter & Type $65 \mathrm{~d}$ & $\begin{array}{c}\text { Online plotter to visualise the } \\
\text { data. }\end{array}$ \\
\hline Water inlet profile & Type $14 \mathrm{~h}$ & Input data for the water inlet. \\
\hline Calculator & Equation & $\begin{array}{c}\text { Calculator to provide the } \\
\text { load profile parameters. }\end{array}$ \\
\hline Controller & Type $2 \mathrm{~b}$ & $\begin{array}{c}\text { Controller to turn the water } \\
\text { pump on and off. }\end{array}$ \\
\hline Centrifugal Pump & Type 114 & Water pump. \\
\hline
\end{tabular}

Table 4: Design parameters for the system components in TRNSYS. 


\begin{tabular}{|c|c|c|c|}
\hline Component & Parameter & Value & TRNSYS Unit \\
\hline \multirow{7}{*}{ HPHE } & $\begin{array}{l}\text { Specific heat of source } \\
\text { side fluid }\end{array}$ & $\begin{array}{l}\text { Varied with } \\
\text { temperature }\end{array}$ & $\mathrm{kJ} \cdot \mathrm{kg}^{-1} \cdot \mathrm{K}^{-1}$ \\
\hline & $\begin{array}{l}\text { Specific heat of load } \\
\text { side fluid }\end{array}$ & 4.182 & $\mathrm{~kJ} \cdot \mathrm{kg}^{-1} \cdot \mathrm{K}^{-1}$ \\
\hline & $\begin{array}{l}\text { Conductance of the } \\
\text { exchanger }\end{array}$ & $\begin{array}{l}\text { Calculated using } \\
\text { Equation } 1\end{array}$ & $\mathrm{~W} \cdot \mathrm{K}^{-1}$ \\
\hline & $\begin{array}{c}\text { Source side inlet } \\
\text { temperature }\end{array}$ & $\begin{array}{c}\text { Taken from } \\
\text { Temperature Data }\end{array}$ & ${ }^{\circ} \mathrm{C}$ \\
\hline & Source side flow rate & $\begin{array}{c}\text { Taken from Fan } \\
\text { speed data. Converted } \\
\text { using Equation } 9\end{array}$ & $\mathrm{~kg} \cdot \mathrm{hr} r^{-1}$ \\
\hline & $\begin{array}{l}\text { Load side inlet } \\
\text { temperature }\end{array}$ & Taken from calculator & ${ }^{\circ} \mathrm{C}$ \\
\hline & Load side flow rate & $\begin{array}{l}480 \text { for Simulations } \\
1,2 \text { and } 4 \\
1320 \text { for Simulations } \\
3 \text { and } 5\end{array}$ & $\mathrm{~kg} \cdot \mathrm{hr}^{-1}$ \\
\hline Extraction Fan & Rated flow rate & 1000 & kg.hr ${ }^{-1}$ \\
\hline \multirow{2}{*}{ Centrifugal Pump } & Rated flow rate & 1320 & kg.hr $r^{-1}$ \\
\hline & Fluid specific heat & 4.182 & $\mathrm{~kJ} \cdot \mathrm{kg}^{-1} \cdot \mathrm{K}^{-1}$ \\
\hline
\end{tabular}

The overall conductance value (UA) required for the simulation, found by multiplying the heat transfer surface area $\left(\mathrm{A}, \mathrm{m}^{2}\right)$ by overall heat transfer coefficient $\left(\mathrm{U}, \mathrm{W} \cdot \mathrm{m}^{2} \cdot \mathrm{K}^{-1}\right)$ of the HPHE, was determined from the experimental data using Equations 1-5. The Logarithmic Mean Temperature Difference (LMTD) method for a cross-flow heat exchanger was deemed appropriate over the effectiveness- Number of Transfer Units ( $\varepsilon$-NTU) method as the outlet temperatures from experimental data was available and there was no phase change of the fluids within the heat exchanger [31].

$$
U A=\frac{\dot{Q}}{\Delta T_{l m}}
$$

where

$$
\dot{Q}=\dot{m}_{s} \times c_{p s} \times\left(T_{h, \text { in }}-T_{h, \text { out }}\right)
$$

and

$$
\Delta T_{l m}=\frac{\Delta T_{1}-\Delta T_{2}}{\ln \left(\Delta T_{1} / \Delta T_{2}\right)}
$$

where

$\Delta T_{1}=T_{h, \text { in }}-T_{c, \text { out }}$

and

$$
\Delta T_{2}=T_{h, o u t}-T_{c, \text { in }}
$$

$\dot{Q}$ is the heat transfer rate, $\Delta T_{l m}$ is the LMTD, $\dot{m}_{s}$ is the mass flow rate of the source fluid, $c_{p s}$ is the specific heat capacity of the source fluid, $\Delta T_{1}$ is the difference between the hot source fluid inlet $\left(T_{h, i n}\right)$ and cold sink outlet temperatures $\left(T_{c, \text { out }}\right)$ and $\Delta T_{2}$ is the difference between the hot source fluid outlet $\left(T_{h, \text { out }}\right)$ and cold sink inlet temperatures $\left(T_{c, \text { in }}\right)$. 
The exhaust gas flow rate was measured in $\mathrm{Nm}^{3} \cdot \mathrm{hr}^{-1}$, which had to be converted into $\mathrm{kg}^{-\mathrm{hr}^{-1}}$ for the TRNSYS simulation. In order to do this, the ideal gas law equation was used, shown in Equations 6-9.

$$
P \times \dot{V}=n \times R \times T
$$

where

$$
n=\frac{\dot{m}}{M}
$$

Substituting for $n$

$$
P \times \dot{V}=\frac{\dot{m}}{M} \times R \times T
$$

Rearranging

$$
\dot{m}=\frac{P \times \dot{V} \times M}{R \times T}
$$

$P$ is the pressure of the gas, $\dot{V}$ is the volumetric flow, $n$ is the number of moles of gas, $R$ is the universal gas constant, $T$ is the absolute temperature of the gas, $\dot{m}$ is the mass flow of the exhaust gas and $M$ is the molecular weight of gas.

Five simulations were conducted in total, which replicated the inlet conditions of the experimental set-up to aid comparison. The process for Simulation 1 is described below with all further simulations following the same process with the varying parameters described in Table 5.

For Simulation 1, a 228-minute temperature profile from the kiln's exhaust was fed into the heat exchanger with parameters chosen to reflect the HPHE design. The exhaust gas temperature inlet was transient. There were 5 second time steps for the data points, an average temperature of $138^{\circ} \mathrm{C}$ with a variation of $7^{\circ} \mathrm{C}$. The variable speed exhaust fan flow rate data was input from experimental results to simulate the volume and flow rate of exhaust gas passing through the HPHE. The load profile of water was fed into a calculator in order to provide a constant flow of water at $480 \mathrm{~kg} \cdot \mathrm{hr}^{-1}$. The daily load output fed into a variable water pump to provide the infeed volume, a constant temperature of $25^{\circ} \mathrm{C}$ and flow rate of water to the HPHE. A controller was used to turn the pump on and off depending on the inlet temperature of the water. For the purpose of these simulations, the pump was continuously on, reflecting the experimental setup. Input and output values of the model were fed into an online plotter to visualise the results in graphical form. The outlet temperatures were averaged when a steady state was reached and are provided in the results section. 
Table 5: Simulation Input Parameters.

\begin{tabular}{|c|c|c|c|c|c|c|c|c|c|}
\hline \multirow{2}{*}{ Simulation } & \multirow{2}{*}{ Condition } & \multirow{2}{*}{$\begin{array}{c}\text { Fan Speed, } \\
\mathrm{Hz}\end{array}$} & \multirow{2}{*}{$\begin{array}{c}\text { Av. Exhaust } \\
\text { Inlet, }{ }^{\circ} \mathbf{C}\end{array}$} & \multicolumn{2}{|c|}{ Av. Exhaust Mass Flow Rate } & \multirow{2}{*}{$\begin{array}{c}\text { Water } \\
\text { Inlet, }{ }^{\circ} \mathrm{C}\end{array}$} & \multicolumn{2}{|c|}{ Water Mass Flow Rate } & \multirow[b]{2}{*}{ Time Period, mins } \\
\hline & & & & kg.hr $\mathbf{r}^{-1}$ & kg.s ${ }^{-1}$ & & kg.hr-1 & kg.s ${ }^{-1}$ & \\
\hline \multirow{6}{*}{1} & 1 & 25 & 133.5 & 673 & 0.187 & \multirow{6}{*}{25.0} & \multirow{6}{*}{480} & \multirow{6}{*}{$0.1 \dot{3}$} & $0-28$ \\
\hline & 2 & 30 & 139.1 & 791 & 0.220 & & & & $28-70$ \\
\hline & 3 & 35 & 140.2 & 903 & 0.251 & & & & $70-115$ \\
\hline & 4 & 40 & 139.5 & 1052 & 0.292 & & & & $115-148$ \\
\hline & 5 & 45 & 139.3 & 1169 & 0.325 & & & & $148-195$ \\
\hline & 6 & 50 & 136.2 & 1298 & 0.361 & & & & $195-228$ \\
\hline \multirow{6}{*}{2} & 1 & 25 & 218.8 & 625 & 0.174 & \multirow{6}{*}{20.0} & \multirow{6}{*}{480} & \multirow{6}{*}{$0.1 \dot{3}$} & $0-46$ \\
\hline & 2 & 30 & 224.6 & 720 & 0.200 & & & & $46-95$ \\
\hline & 3 & 35 & 228.8 & 848 & 0.236 & & & & $95-136$ \\
\hline & 4 & 40 & 231.4 & 964 & 0.268 & & & & $136-179$ \\
\hline & 5 & 45 & 234.3 & 1057 & 0.294 & & & & $179-258$ \\
\hline & 6 & 50 & 235.6 & 1149 & 0.319 & & & & $258-300$ \\
\hline \multirow{3}{*}{3} & 1 & 25 & 222.9 & 628 & 0.174 & \multirow{3}{*}{20.8} & \multirow{3}{*}{1320} & \multirow{3}{*}{$0.3 \dot{6}$} & $0-33$ \\
\hline & 2 & 35 & 230.1 & 873 & 0.243 & & & & $33-78$ \\
\hline & 3 & 50 & 235.7 & 1192 & 0.331 & & & & $78-124$ \\
\hline \multirow{5}{*}{4} & 1 & 25 & 262.0 & 633 & 0.176 & \multirow{5}{*}{18.0} & \multirow{5}{*}{480} & \multirow{5}{*}{$0.1 \dot{3}$} & $0-27$ \\
\hline & 2 & 30 & 268.0 & 732 & 0.203 & & & & $27-56$ \\
\hline & 3 & 35 & 264.0 & 835 & 0.232 & & & & $56-88$ \\
\hline & 4 & 40 & 266.0 & 944 & 0.262 & & & & $88-142$ \\
\hline & 5 & 45 & 269.0 & 1027 & 0.285 & & & & $142-206$ \\
\hline \multirow{4}{*}{5} & 1 & 25 & 262.0 & 612 & 0.170 & \multirow{4}{*}{18.0} & \multirow{4}{*}{1320} & \multirow{4}{*}{$0.3 \dot{6}$} & $0-22$ \\
\hline & 2 & 35 & 265.0 & 860 & 0.239 & & & & $22-43$ \\
\hline & 3 & 45 & 270.0 & 1076 & 0.299 & & & & $43-68$ \\
\hline & 4 & 50 & 272.0 & 1180 & 0.328 & & & & $68-110$ \\
\hline
\end{tabular}




\subsection{Full Scale Unit Return on Investment}

New WHR technology is not likely to be widely adopted for mainstream use unless is has a reasonable return on investment (ROI); the authors consider this to be around 36 months or 3 years. ROI is used in this paper as it the most commonly used straightforward performance method and evaluation metrics in business analysis for evaluating investments. ROI highlights the profitability of an investment in this innovative technology and in turn it is simply understood by the reader. Furthermore, the parameters required to calculate the ROI are easily accessible. This section deals with a ROI analysis of a multi-pass water heat sink HPHE unit scaled for a full-scale CRK installation to determine the potential payback. ROI measures the gain or loss generated on an investment relative to the amount of money invested and is typically seen as a percentage per year or the amount of time taken to break even, shown by Equations 10 and 11, respectively.

$$
R O I=\frac{\text { Net Profit }}{\text { Cost of Investment }} \times 100
$$

or:

$$
\text { ROI }=\frac{\text { Cumulative Cash Flow }}{\text { Annual Net Benefit }} \times 12 \text { (months) }
$$

Net profit represents profit after all operating costs. Cost of investment is all related costs. For this design, costs have been attributed to initial capital and ongoing installation, operational and maintenance costs. Cumulative Cash Flow is the system cost. Annual Net Benefit (ANB) is the savings attributed to the installation. In this case reduced energy consumption and reduction in carbon emissions minus operating and maintenance costs and additional operating expenditures like increased electricity, described by Equations 12-17:

$$
A N B=C_{\text {saved_NG }}+C_{\text {CO2_emissions_saved }}-E_{P}-C_{O \& M}
$$

where:

$$
C_{\text {saved_NG }}=P \dot{Q}_{N G_{-} \text {saved }} \times C_{N G} \times R_{\text {time }, H P H E}
$$

and

$$
C_{\text {CO2_emissions_saved }}=m_{\text {CO2_saved }} \times C_{\text {CO2_emission }}
$$

and

$$
E_{P}=C_{E l} \times Q_{P} \times R_{\text {time,HPHE }}
$$

and

$$
P \dot{Q}_{N G_{-} \text {saved }}=\dot{Q} \times E f f_{P E N}
$$

and

$$
m_{\text {CO2_saved }}=P \dot{Q}_{N G_{-} s a v} \times F_{N G}
$$

Table 6 describes the description, symbols, and units for how the ROI was calculated using Equations 12-17.

Table 6: Description, symbol, value and units used to determine ROI.

\begin{tabular}{|c|c|c|c|}
\hline Description & Symbol & Value & Unit \\
\hline Reduction in natural gas saving & $C s_{\text {aved_NG }}$ & $P \dot{Q}_{N G, \text { saved }} \times C_{N G} \times R_{\text {time,HPHE }}$ & $£ . \mathrm{yr}^{-1}$ \\
\hline Total $\mathrm{CO}_{2}$ cost saving & $C_{C O 2_{\_} \text {emission_saved }}$ & $m_{C O 2_{\text {_aved }}} \times C_{C O 2_{\text {_emission }}}$ & $£ . \mathrm{yr}^{-1}$ \\
\hline Parasitic load energy cost & $E_{P}$ & $C_{E l} \times Q_{P} \times R_{\text {time,HPHE }}$ & $£ . \mathrm{yr}^{-1}$ \\
\hline Cost of maintenance & $C_{O \& M}$ & & $£ . \mathrm{yr}^{-1}$ \\
\hline Primary energy savings & $P \dot{Q}_{N G, \text { sav }}$ & $\dot{Q}^{*} E f f f_{\text {pen }}$ & $\mathrm{MWh}$ \\
\hline
\end{tabular}




\begin{tabular}{|c|c|c|c|}
\hline Natural gas cost & $C_{N G}$ & & $£ . \mathrm{MWh}^{-1}$ \\
\hline Working hours of the system per year & $R_{\text {time,HPHE }}$ & & hr. $y^{-1}$ \\
\hline Mass of $\mathrm{CO}_{2}$ emissions prevented & $m_{\mathrm{CO} 2 \text { saved }}$ & $P \dot{Q}_{N G, \text { saved }} x F_{N G}$ & $\mathrm{t}_{\mathrm{CO} 2 \mathrm{eq}} \cdot \mathrm{y}^{-1}$ \\
\hline $\mathrm{CO}_{2}$ emission cost & $C_{C O 2 \_ \text {emission }}$ & $18.75[32]$ & £.tCO $\mathrm{e}^{-1}$ \\
\hline Electrical energy cost & $C_{E l}$ & & £.MWh-1 \\
\hline Additional electricity load & $Q_{P}$ & & $\mathrm{~kW}$ \\
\hline $\begin{array}{c}\text { Thermal power recovered by the } \\
\text { HPHE }\end{array}$ & $\dot{Q}$ & $\dot{m} \times C_{p} \times\left(T_{h, \text { in }}-T_{h, \text { out }}\right)$ & $\mathrm{J} . \mathrm{s}^{-1}(\mathrm{~W})$ \\
\hline $\begin{array}{c}\text { Conversion factor to determine } \\
\text { weight of natural gas saved per MWh }\end{array}$ & $F_{N G}$ & 215.86 & $\mathrm{~kg}_{\mathrm{CO} 2} \cdot \mathrm{MWh}^{-1}$ \\
\hline Well to tank factor & Eff $f_{P e n}$ & 1.01 & - \\
\hline
\end{tabular}

For the $\mathrm{CO}_{2}$ emission cost, Euro currency values were converted to Pound Sterling. At the time of writing $£ 1.00$ was equivalent to $€ 1.16$.

\subsubsection{Thermal Design of Full-Scale Unit}

In order to determine the ROI, a theoretical full-scale unit has to be reasonably designed and costed. A $700 \mathrm{~kW}$ unit was designed including installation costs for a full scale kiln recovering waste heat from an exhaust streams of $245^{\circ} \mathrm{C}$. This recoverable energy content was chosen to reflect full scale unit duty designs already seen in the literature [23]. The end use chosen for the heat sink stream and the temperature required is site specific and largely irrelevant to the ROI calculations. The calculations assume that the $700 \mathrm{~kW}$ recovered is used to replace 700 $\mathrm{kW}$ of natural gas use. However, the end use in this case was raising the temperature of water from 60 to $90^{\circ} \mathrm{C}$ for space heating or hot water purposes within a heating loop. The exhaust gas temperature was lowered to $155^{\circ} \mathrm{C}$ from $245^{\circ} \mathrm{C}$, to keep temperatures above gas condensation levels. The specific heat capacities were set for the corresponding temperatures. The mass flow rates were determined using Equation 2. The designed unit's thermal design parameters are highlighted in Table 7.

Table 7: Design parameters of full-scale installation.

\begin{tabular}{|c|c|c|}
\hline \multicolumn{3}{|c|}{ Mass Flow Rates } \\
\hline Exhaust source fluid & 26,000 & \multirow{2}{*}{$\mathrm{k} \mathrm{kg} \cdot \mathrm{hr}{ }^{-1}$} \\
\hline Water sink fluid & 20,000 & \multirow{2}{*}{$\mathrm{*} \mathrm{kJ} . \mathrm{kg}^{-1} \cdot \mathrm{K}^{-1}$} \\
\hline Exhaust & 1.077 & \\
\hline Water & 4.200 & \multirow{2}{*}{${ }^{\circ} \mathrm{C}$} \\
\hline Exhaust Inlet & 245 & \\
\hline Exhaust Outlet & 155 & \\
\hline Water Inlet & 60 & \multirow{2}{*}{$\mathrm{kW}$} \\
\hline Water Outlet & 90 & \\
\hline \multicolumn{2}{|c|}{ Heat Recovery Rate } \\
\hline Total Duty of the Unit & 700 & \\
\hline
\end{tabular}




\section{Results}

\subsection{Experimental Results}

Figure 10 shows the results for Experiment 1 where the exhaust gas temperature was maintained at around $135^{\circ} \mathrm{C}$ and the water sink at $480 \mathrm{~kg} \cdot \mathrm{hr}^{-1}$ over a 228 -minute period. Fan speeds from $25-50 \mathrm{~Hz}$ in intervals of $5 \mathrm{~Hz}$ were trialled with corresponding exhaust mass flow rates between 673 and $1298 \mathrm{~kg} \cdot \mathrm{hr}^{-1}$. As the fan speed increased and more exhaust mass flow was directed through the heat exchanger, both the exhaust outlet temperature and water outlet temperature increased as more heat energy was recovered. This was the case for all the experiments. The average temperatures of the water and exhaust's inlet and outlet temperatures are summarised in Table 9 for each time period and condition in Section 4.2.

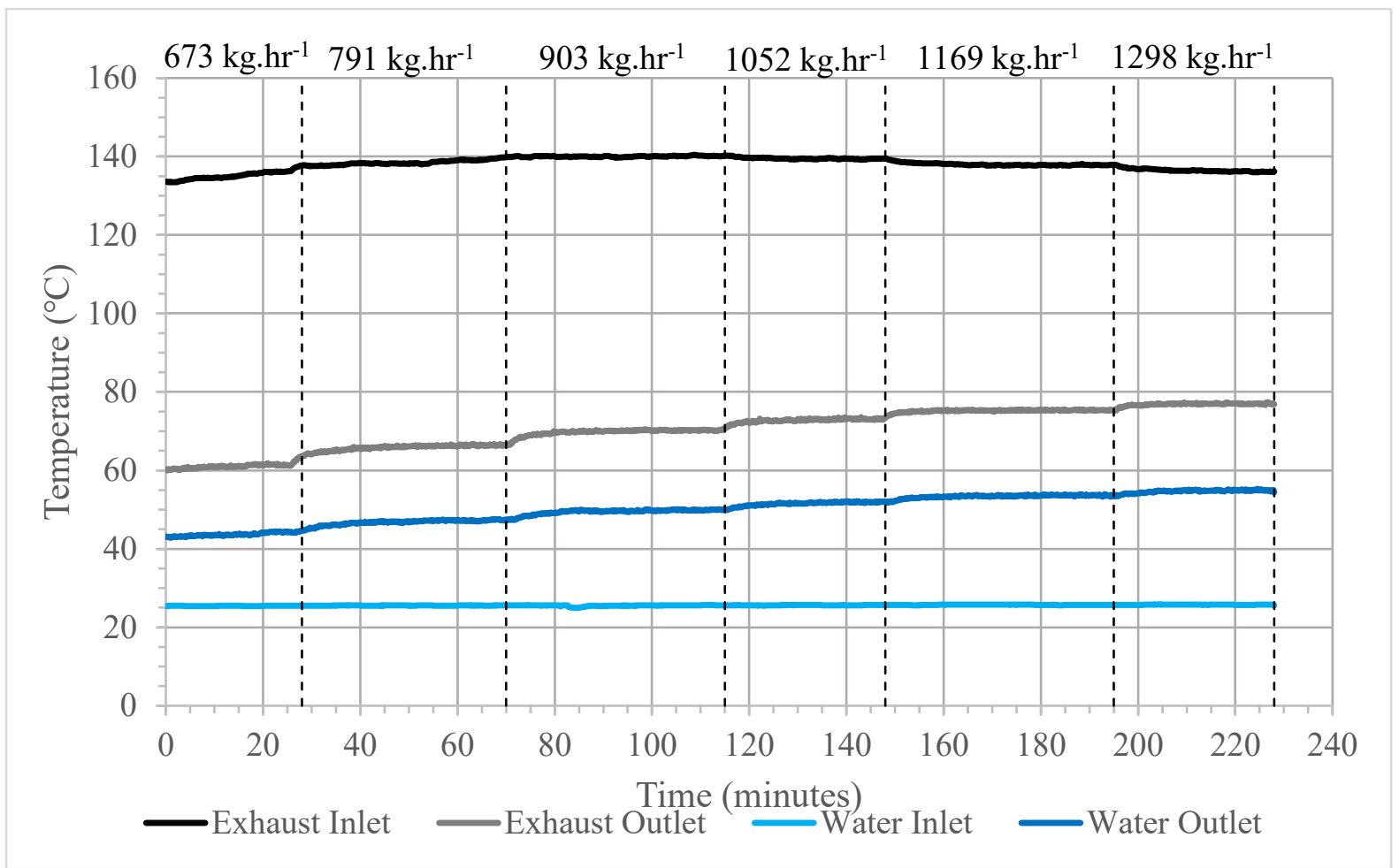

Figure 10: Graph showing the results of Experiment 1, the inlet and outlet temperature of water and exhaust streams at corresponding fan speeds.

Figure 11 shows the exhaust and water inlet and outlet temperatures of the system over the 300 -minute period. The exhaust gas temperature was maintained at around $230^{\circ} \mathrm{C}$ and the water sink at $480 \mathrm{~kg} \cdot \mathrm{hr}^{-1} .25-50 \mathrm{~Hz}$ fan speeds in increments of $5 \mathrm{~Hz}$ were tested to vary the flow rate of combustion exhaust gases through the HPHE. The mass flow of the exhaust ranged from 625-1149 kg.hr-1 . It is seen from Figure 11 that as the frequency of the fan speed is increased, the input and output temperatures of the gases increased. Furthermore, it can be seen that the temperature of the water outlet increased as inlet water temperature remained fairly constant. At these higher temperatures, higher water and exhaust outlet temperatures were seen. 


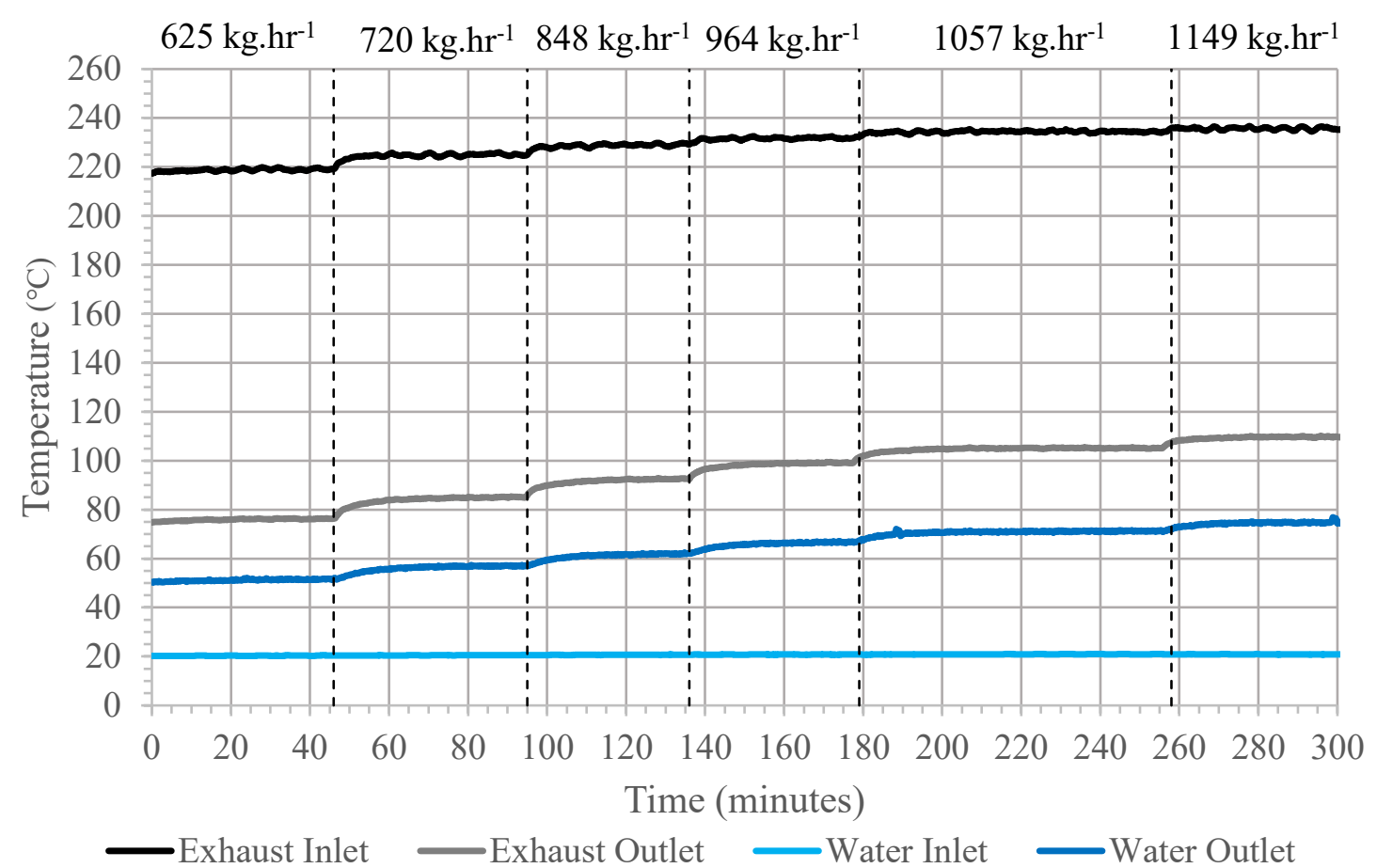

Figure 11: Graph showing the results of Experiment 2, the inlet and outlet temperature of water and exhaust streams at corresponding fan speeds.

Figure 12 shows the exhaust and water inlet and outlet temperatures of the system over the 124-minute period. The exhaust gas temperature was maintained around $230^{\circ} \mathrm{C}$ and the water sink at $1320 \mathrm{~kg} \cdot \mathrm{hr}^{-1} .25,35$ and $50 \mathrm{~Hz}$ fan speeds were tested. The mass flow of the exhaust ranged from $628-1192 \mathrm{~kg} \cdot \mathrm{hr}^{-1}$.

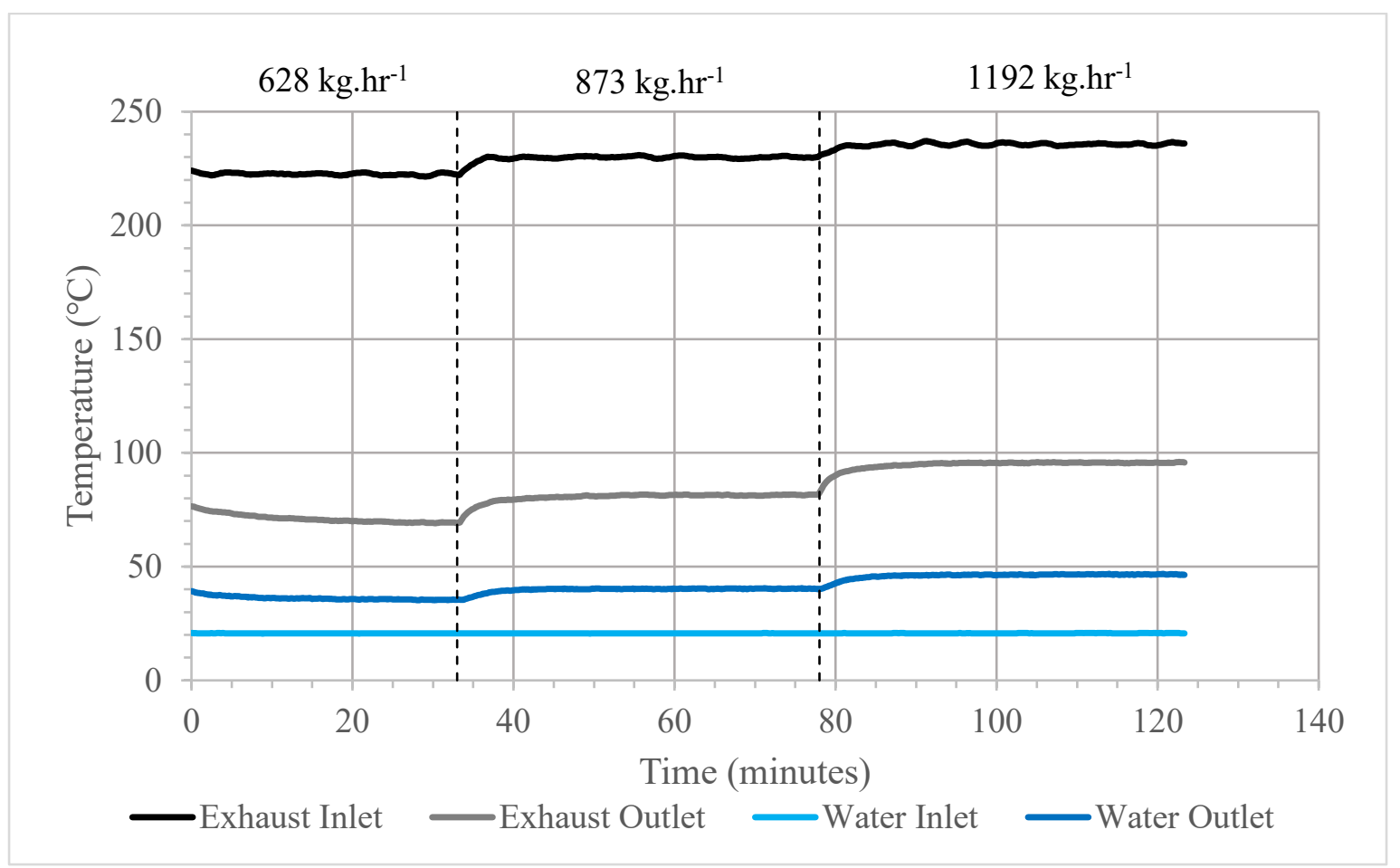

Figure 12: Graph showing the results of Experiment 3, the inlet and outlet temperature of water and exhaust streams at corresponding fan speeds. 
Figure 13 shows the exhaust and water inlet and outlet temperatures of the system over a 206minute period. The exhaust gas temperature was maintained at around $265^{\circ} \mathrm{C}$ and the water sink at $480 \mathrm{~kg} \cdot \mathrm{hr}^{-1} .25-45 \mathrm{~Hz}$ fan speeds in increments of $5 \mathrm{~Hz}$ were tested. The mass flow of the exhaust ranged from 633-1027 kg.hr-1. With Experiment 4, the test conditions were not measured continuously as with the previous experiments, for this reason, the data at relevant conditions were spliced when relevant conditions were seen, to provide Figure 13.

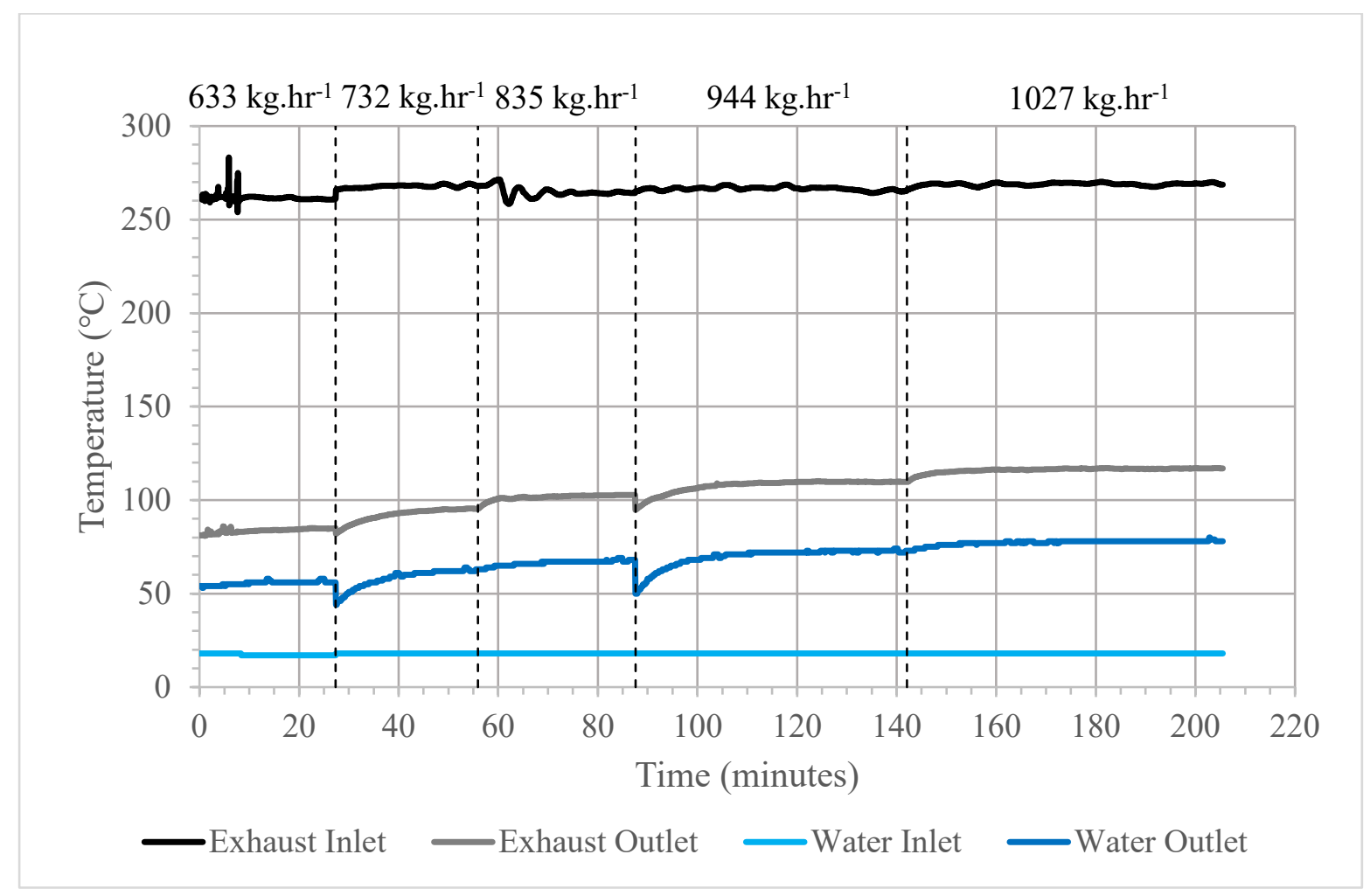

Figure 13: Graph showing the results of Experiment 4, the inlet and outlet temperature of water and exhaust streams at corresponding fan speeds.

Figure 14 shows the exhaust and water inlet and outlet temperatures of the system over a 110minute period. The exhaust gas temperature was maintained at around $265^{\circ} \mathrm{C}$ and the water sink at $1320 \mathrm{~kg} \cdot \mathrm{hr}^{-1} .25,35,45$ and $50 \mathrm{~Hz}$ fan speeds were tested. The mass flow of the exhaust ranged from 612-1180 kg.hr-1. As with Experiment 4, Experiment 5 conditions were not experienced in one continuous time period. For this reason, the data provided was spliced from the desirable monitored period. This explains the spikes when transitioning between fan speed values seen in Figure 14. Due to these spikes, average temperatures and conductance values were only calculated when steady state conditions were seen. 


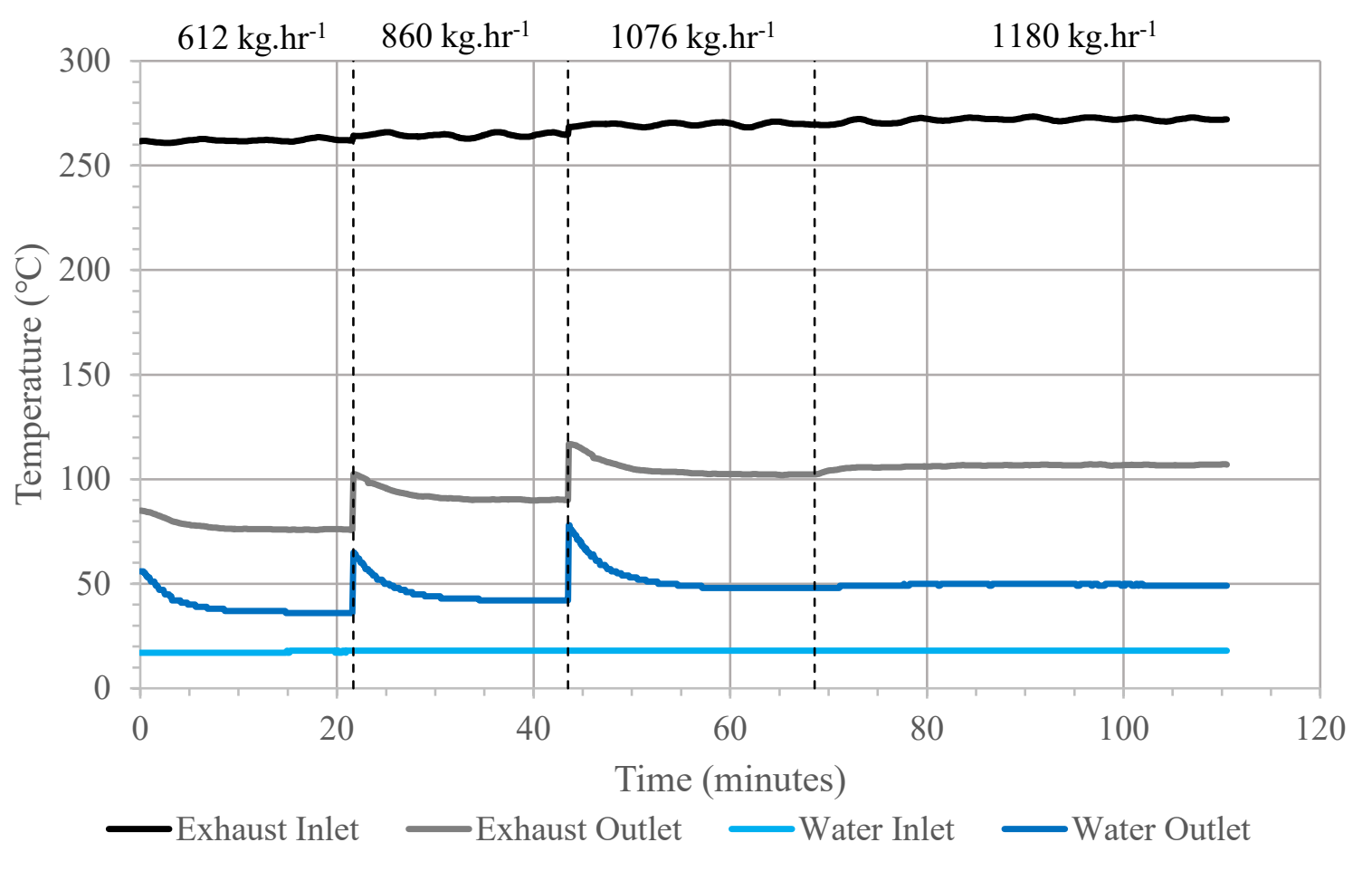

Figure 14: Graph showing the results of Experiment 5, the inlet and outlet temperature of water and exhaust streams at corresponding fan speeds.

\subsection{Simulation Results Compared With Experimental Results}

Figures 15-19 show the experimental outlet temperatures compared with the simulation results for Experiments 1-5, respectively. It can be seen across all the experiments and simulations that as the mass flow rate of the exhaust stream increased, the temperature of both the water and exhaust outlets increased. Additional mass flow through the system meant more energy was extracted as seen by the increased water outlet temperature. However, the temperature of the exhaust was reduced by a lesser extent. The simulations showed higher temperatures than the experimental setup. The percentage difference between the simulation and experimental results for the outlet temperatures of the water and exhaust are tabulated in Table 9 in Section 4.2 . 


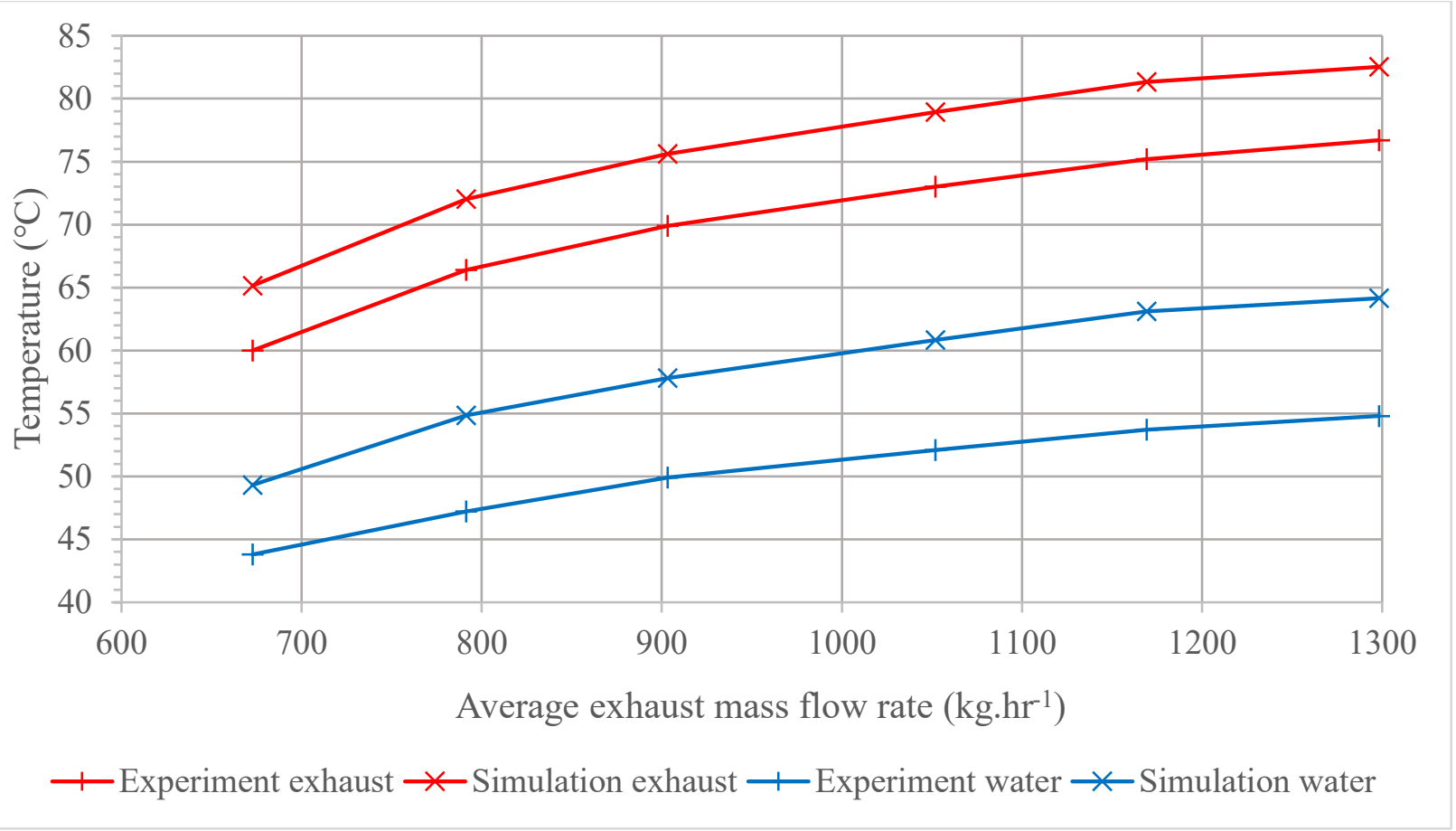

Figure 15: Graph showing the exhaust and water outlet temperatures for Experiment and Simulation 1.

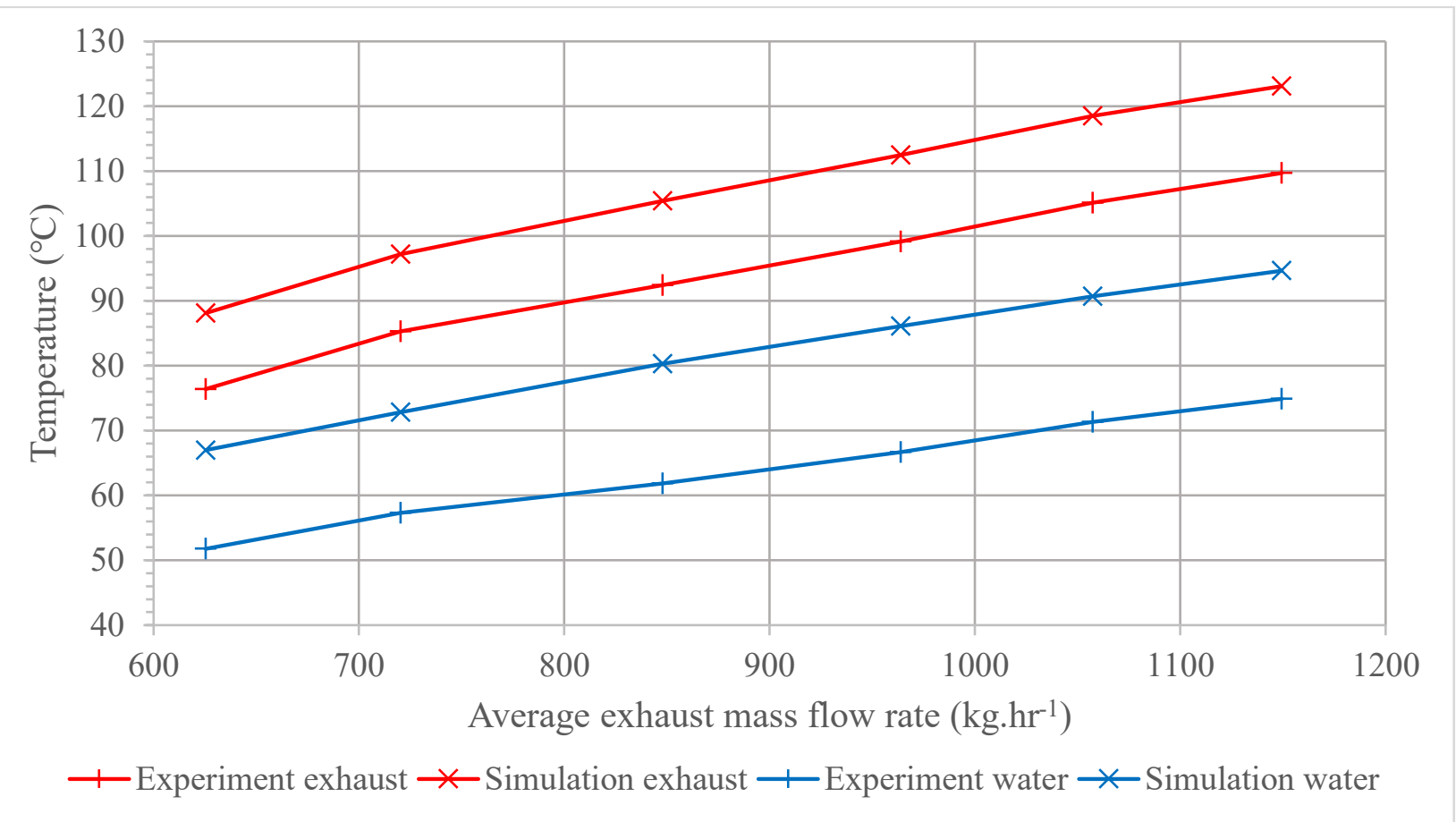

Figure 16: Graph showing the exhaust and water outlet temperatures for Experiment and Simulation 2. 


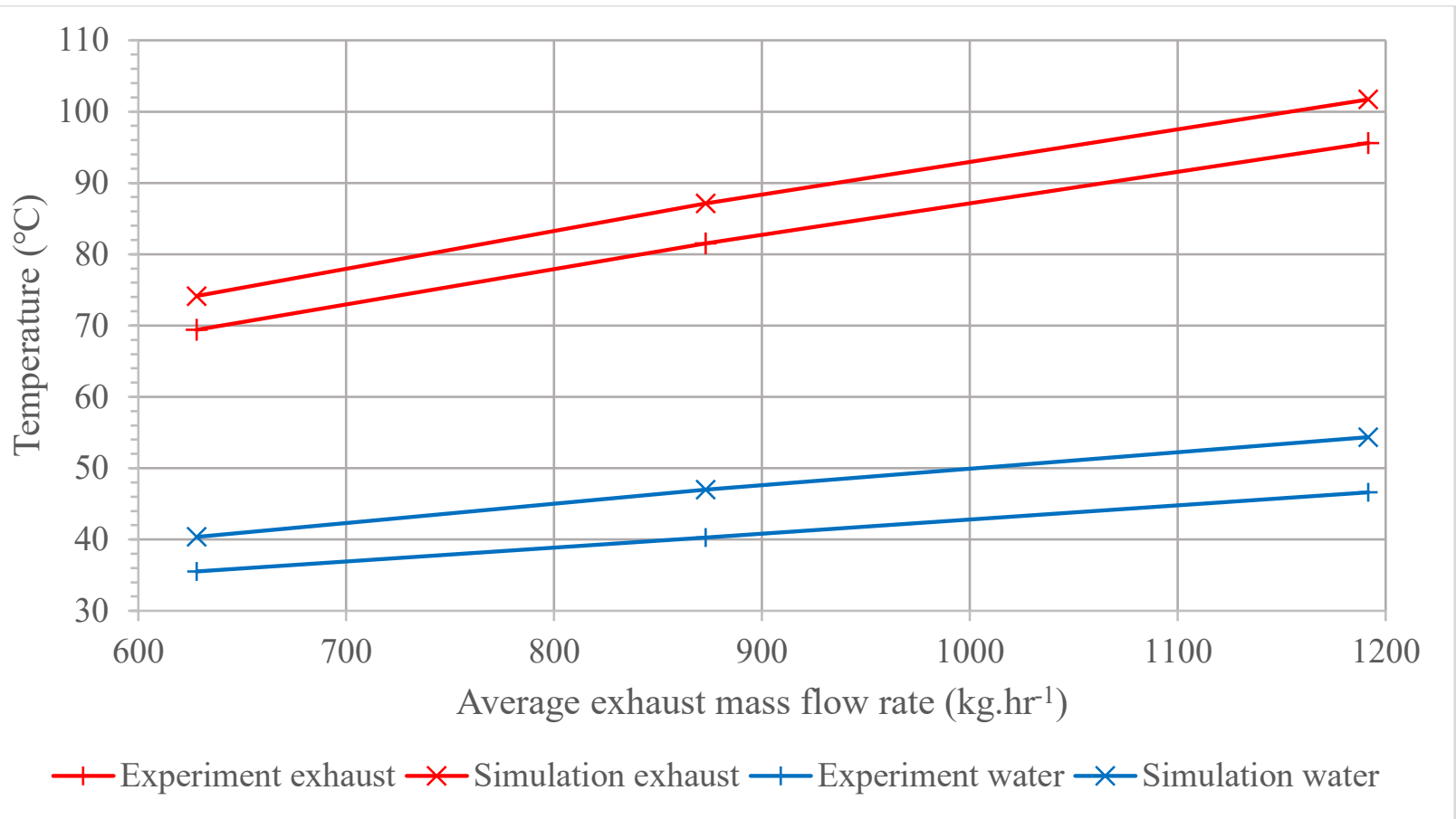

Figure 17: Graph showing the exhaust and water outlet temperatures for Experiment and Simulation 3.

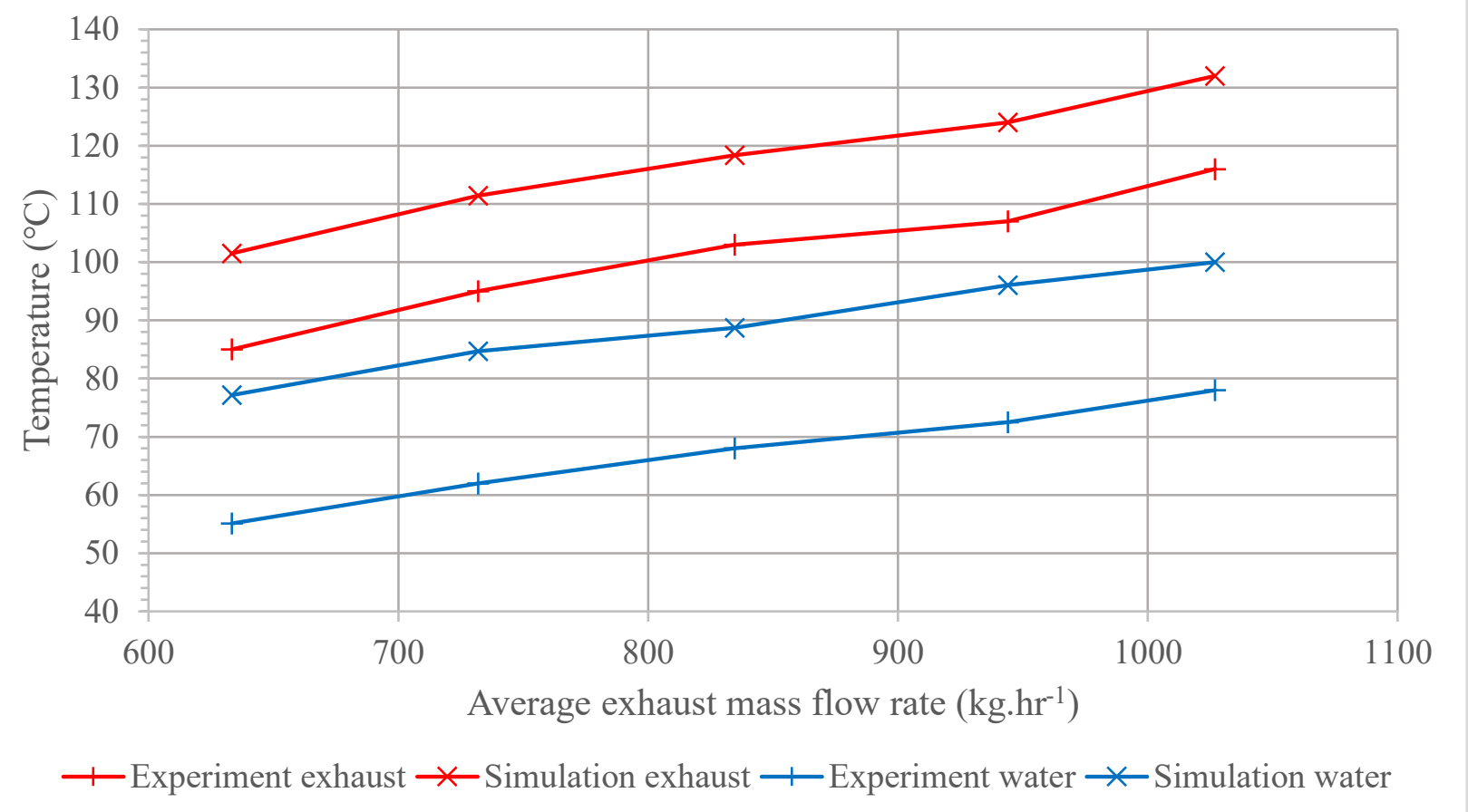

Figure 18: Graph showing the exhaust and water outlet temperatures for Experiment and Simulation 4. 


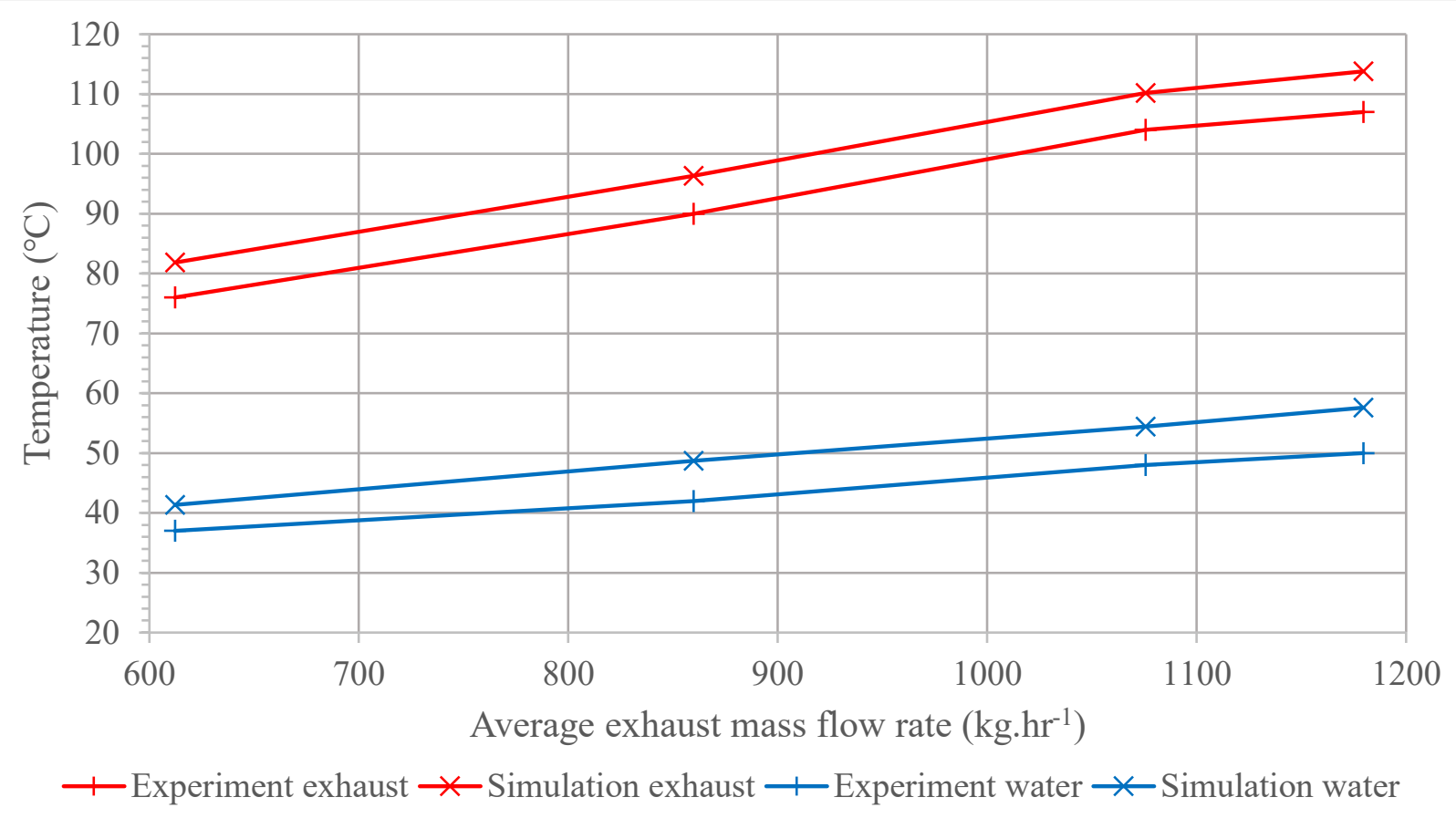

Figure 19: Graph showing the exhaust and water outlet temperatures for Experiment and Simulation 5.

\subsection{Return on Investment Results}

A $700 \mathrm{~kW}$ unit was scaled to recover available waste heat. 6,300 hours were chosen as the number of operating hours per year, roughly $70 \%$ of available time per year. This was in order to take into account maintenance and shut down periods and is a conservative estimate. As water is released as a product of combustion of natural gas, it absorbs heat energy generated and does not contribute to the work done by the combustion process. $4 \%$ thermal losses have been considered due to the heat transfer circuit and so primary energy saving is lower than the thermal energy transferred to the secondary stream. The electricity cost was considered to be $£ 0.13$ per kWh with an annual energy cost increase of $2.5 \%$. Annual inflation of $2.5 \%$ was also considered. Carbon trade prices were considered at $£ 18.75$ per tonne. A writing down allowance of $18 \%$ was used and UK tax of $20 \%$. Figure 20 shows the cash flow for the installation over a 10-year period with corresponding annual and cumulative cashflows. It can be seen that the investment pays for itself in year 3, specifically at around 33 months, within the reasonable time period of 36 months. It is concluded that this installation can provide a very reasonable ROI, even when assuming lower than ideal conditions. shows the specific variables and values used to calculate ROI for this analysis.

Table 8: Variables and values used for calculating the ROI.

\begin{tabular}{|c|c|c|}
\hline Variable & Value & Unit \\
\hline $\begin{array}{c}\text { Unit Duty, Thermal energy transferred to secondary } \\
\text { stream }\end{array}$ & 700 & $\mathrm{~kW}$ \\
\hline Parasitic load & 30 & $\mathrm{~kW}$ \\
\hline Working hours & 6,300 & $\mathrm{hr} . \mathrm{y}^{-1}$ \\
\hline Thermal energy transferred to water per year & 4,410 & $\mathrm{MWh}^{-1}$ \\
\hline Conversion of natural gas saved per MWh, $F_{N G}$ & 215.86 & $\mathrm{kgCO}_{\mathrm{CW}} \cdot \mathrm{MWh}^{-1}$ \\
\hline Conversion factor for natural gas, $E f f_{P E N}$ & 1.01 & \\
\hline Natural Gas Cost, $C_{N G}$ & 29.6 & $£ . \mathrm{MWh}^{-1}$ \\
\hline
\end{tabular}




\begin{tabular}{|c|c|c|}
\hline Reduction in fuel Cost, $C_{S a v}{ }_{N G}$ & 125,351 & $£ . \mathrm{yr}^{-1}$ \\
\hline Conv $_{F N G}$ & 215.86 & $\mathrm{~kg}_{\mathrm{CO} 2} \cdot \mathrm{MWh}^{-1}$ \\
\hline Mass of $\mathrm{CO}_{2}$ saved, $\mathrm{m}_{\mathrm{CO} 2}$ saved & 961 & $t_{\mathrm{CO} 2 \mathrm{e}} \mathrm{y}^{-1}$ \\
\hline Cost of $\mathrm{CO}_{2}$ emissions, $\mathrm{C}_{\mathrm{CO} 2}$ emission & $18.75[32]$ & $£ . \mathrm{tCO}_{\mathrm{CO}} \mathrm{e}^{-1}$ \\
\hline$C_{\mathrm{CO} 2}$ emission saved & 17,849 & $£ . \mathrm{yr}^{-1}$ \\
\hline Total saving per year & 143,200 & £.yr-1 \\
\hline Capital Expenditure (Unit and Installation cost) & 350,000 & $£$ \\
\hline ROI (payback period) & 32.8 & Months \\
\hline ROI & 36.6 & $\%$ \\
\hline
\end{tabular}

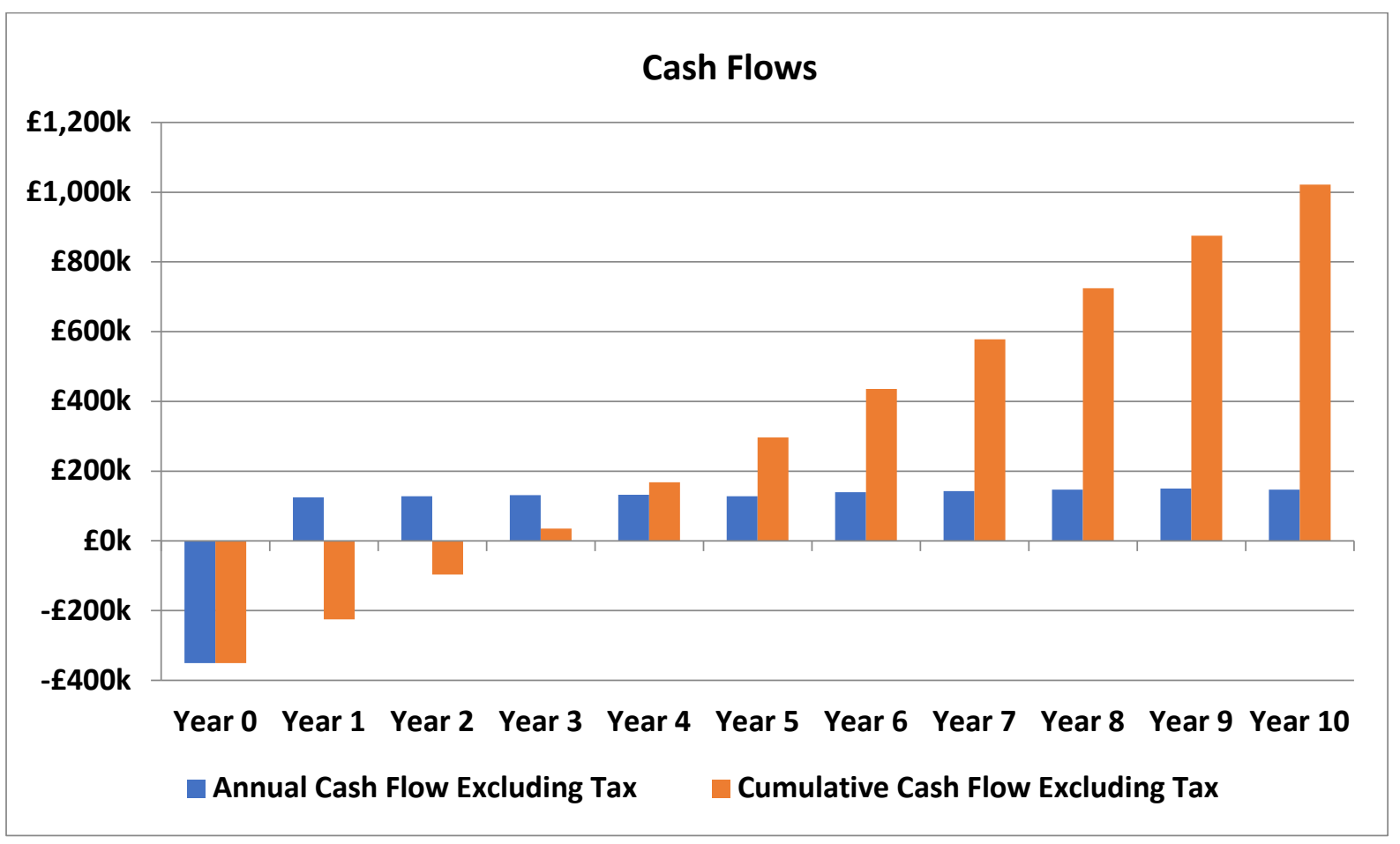

Figure 20: A graph showing the annual and cumulative cash flows of the full-scale installation with payback period.

\section{Further Discussion and Analysis of Results}

\subsection{Study Limitations}

There were some insurmountable limitations of the TRNSYS model compared to the reality of experimental results. Firstly, the water temperature was kept constant in the TRNSYS model, whereas the experiment had slightly variable water inlet temperatures. For the purpose of the simulation, the difference in temperature was considered so negligible that a fixed temperature was acceptable and therefore fixed $c_{p}$ value. In the future, water inlet temperature could be used in the TRNSYS model from a data file for additional accuracy. Flow rate and temperature rises were gradual in the experiments due to equipment taking time to reach a steady state, whereas with the TRNSYS model, changes were immediate and didn't reflect the equilibrium balance the system had to attain. Therefore, results were only averaged once the system reached a steady state. Furthermore, there are no temperature losses from pipework or equipment i.e. the model assumes perfect insulation, where in reality, some heat would be radiated from pipework and equipment and be lost to atmosphere. For this these reasons, predictably, the simulation consistently predicted higher outlet temperatures for both the gas and water than were seen in the experimental results. The model created is based upon traditional heat 
exchanger equations. Heat pipe heat exchangers perform slightly differently in comparison to the cross-flow model. Future work is required to create a dedicated HPHE component for TRNSYS. Even with these model limitations, the model results reflect the experimental results.

\subsection{Percentage Difference Between Experimental and Simulation Results}

To compare the performance of the HPHE to the TRNSYS model, Table 9 shows a summary of the difference in temperature of the exhaust and water outlet between the experimental and simulated results. The simulation difference in exhaust outlet temperatures were reasonably close to the experimental values obtained, with a difference between $3.1-10.7 \%$ seen. In the condenser section, the difference between the experimental and simulated average water outlet temperatures were higher, between 10.7-35.6\%. This increased difference is believed to be due to inaccuracy when measuring the water mass flow rate. For this reason, when determining the heat transfer rate using Equation 2 for the HPHE, the exhaust measurements were used. 
Table 9: Summary of Experimental and Simulation results with percentage difference

\begin{tabular}{|c|c|c|c|c|c|c|c|}
\hline \multirow[b]{2}{*}{ Simulation } & \multirow[b]{2}{*}{ Condition } & \multicolumn{2}{|c|}{ Experiment } & \multicolumn{2}{|c|}{ Simulation } & \multirow[b]{2}{*}{ Percentage Difference Exhaust } & \multirow[b]{2}{*}{ Percentage Difference Water } \\
\hline & & $\Delta \mathrm{T}$ Exhaust, ${ }^{\circ} \mathrm{C}$ & $\Delta \mathrm{T}$ Water, ${ }^{\circ} \mathrm{C}$ & $\Delta \mathrm{T}$ Exhaust, ${ }^{\circ} \mathrm{C}$ & $\Delta \mathrm{T}$ Water, ${ }^{\circ} \mathrm{C}$ & & \\
\hline \multirow{6}{*}{1} & 1 & 73.5 & 20.3 & 68.4 & 24.3 & $7.0 \%$ & $16.5 \%$ \\
\hline & 2 & 72.7 & 21.6 & 67.1 & 29.9 & $7.7 \%$ & $27.6 \%$ \\
\hline & 3 & 70.3 & 24.2 & 64.6 & 32.8 & $8.1 \%$ & $26.2 \%$ \\
\hline & 4 & 66.5 & 26.4 & 60.6 & 35.8 & $8.9 \%$ & $26.3 \%$ \\
\hline & 5 & 64.1 & 28.0 & 58.0 & 38.1 & $9.6 \%$ & $26.5 \%$ \\
\hline & 6 & 59.5 & 29.0 & 53.7 & 39.2 & $9.8 \%$ & $25.9 \%$ \\
\hline \multirow{6}{*}{2} & 1 & 142.4 & 31.3 & 130.7 & 47.0 & $8.2 \%$ & $33.3 \%$ \\
\hline & 2 & 139.3 & 36.8 & 127.4 & 52.8 & $8.5 \%$ & $30.4 \%$ \\
\hline & 3 & 136.4 & 41.1 & 123.4 & 60.3 & $9.5 \%$ & $31.8 \%$ \\
\hline & 4 & 132.3 & 45.9 & 118.9 & 66.1 & $10.1 \%$ & $30.6 \%$ \\
\hline & 5 & 129.2 & 50.4 & 115.8 & 70.7 & $10.4 \%$ & $28.7 \%$ \\
\hline & 6 & 125.9 & 53.9 & 112.5 & 74.6 & $10.6 \%$ & $27.7 \%$ \\
\hline \multirow{3}{*}{3} & 1 & 153.5 & 14.8 & 148.8 & 19.6 & $3.1 \%$ & $24.2 \%$ \\
\hline & 2 & 148.6 & 19.5 & 143.0 & 26.2 & $3.8 \%$ & $25.5 \%$ \\
\hline & 3 & 140.1 & 25.9 & 134.0 & 33.6 & $4.4 \%$ & $23.0 \%$ \\
\hline \multirow{5}{*}{4} & 1 & 177.0 & 38.1 & 160.5 & 59.2 & $9.3 \%$ & $35.6 \%$ \\
\hline & 2 & 173.0 & 44.0 & 156.6 & 66.7 & $9.5 \%$ & $34.0 \%$ \\
\hline & 3 & 161.0 & 50.0 & 145.6 & 70.7 & $9.6 \%$ & $29.3 \%$ \\
\hline & 4 & 159.0 & 54.5 & 142.0 & 78.0 & $10.7 \%$ & $30.2 \%$ \\
\hline & 5 & 153.0 & 60.0 & 137.0 & 82.0 & $10.5 \%$ & $26.8 \%$ \\
\hline \multirow{4}{*}{5} & 1 & 186.0 & 20.0 & 180.2 & 23.3 & $3.1 \%$ & $14.3 \%$ \\
\hline & 2 & 175.0 & 24.0 & 168.7 & 30.7 & $3.6 \%$ & $21.8 \%$ \\
\hline & 3 & 166.0 & 30.0 & 159.8 & 36.4 & $3.7 \%$ & $17.7 \%$ \\
\hline & 4 & 165.0 & 32.0 & 158.2 & 39.6 & $4.1 \%$ & $19.2 \%$ \\
\hline
\end{tabular}




\subsection{Energy Recovery Rate with Changing Flow Rate}

The performance of a HPHE can be determined by the energy recovery rate from the exhaust and so it is important to know the relationship between energy recovery rate and mass flow rate of the exhaust stream. Figure 21 shows the heat transfer rate $(\mathrm{kW})$ against the exhaust mass flow rate $\left(\mathrm{kg} . \mathrm{hr}^{\mathrm{l}}\right)$ for Experiments 1-5. It can be seen that as the mass flow rate increases, the energy recovery rate increases. Also, across experiments, as the temperature of the exhaust gases increases, the energy recovery rate increases. If the mass flow rate of water through the condenser increases, energy recovery rate also increases. Heat recovery rates were seen between 15.5-63.3 kW for exhaust mass flow rates of 612-1298 kg.hr-1. Experiment 1 shows particularly less energy recovery, but there is roughly $100^{\circ} \mathrm{C}$ difference in exhaust gas temperature between Experiment 1 and Experiments 2-3 but only $30^{\circ} \mathrm{C}$ between Experiments 2-3 and Experiments 4-5. Future work could include filling the gap in temperatures to better characterise the relationship between the heat recovery rate and flow rate.

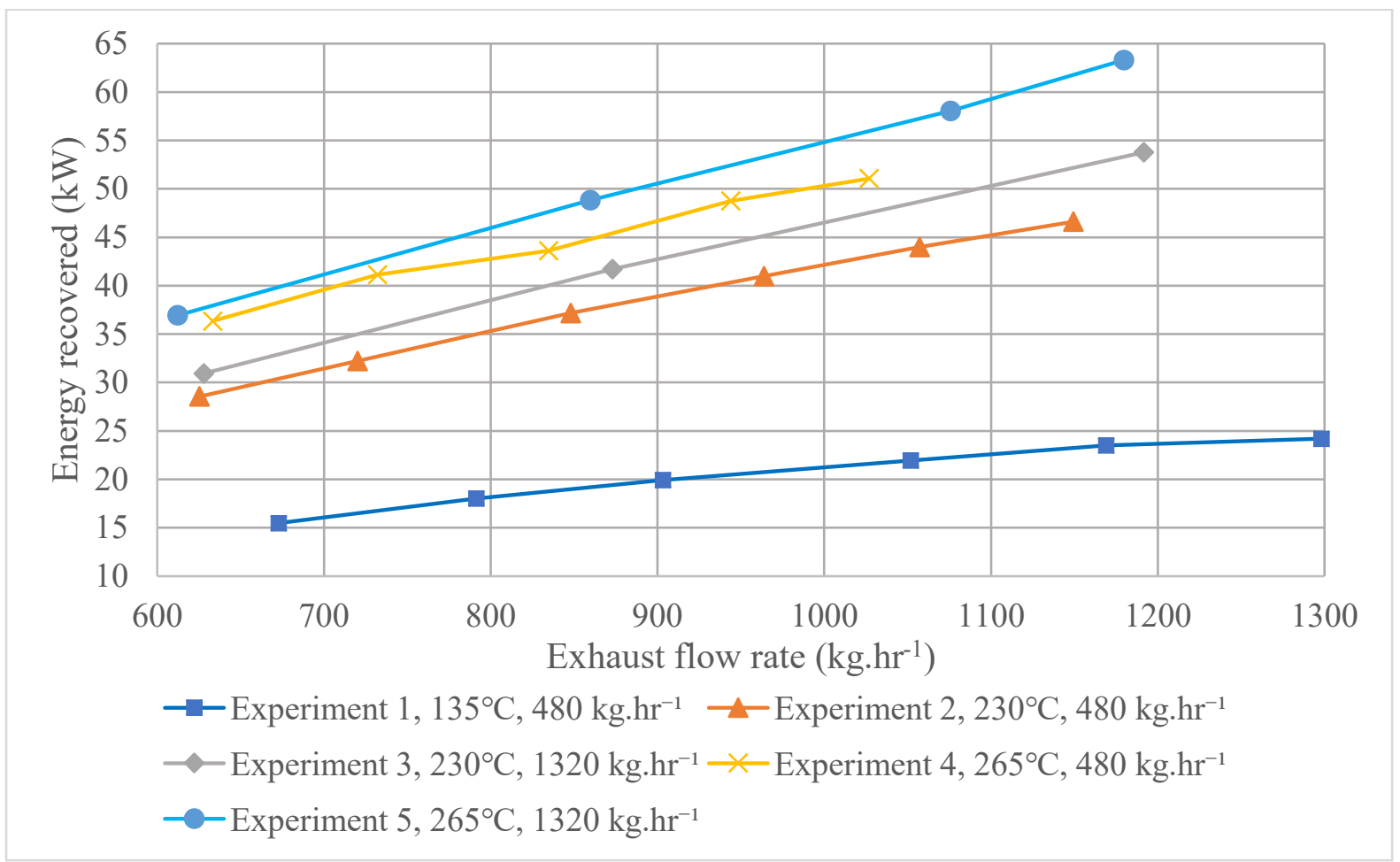

Figure 21: Graph showing energy recovered against flow rate of exhaust gases for each experiment.

The experimental and simulated energy recovery results were compared in Figure 22. It can be seen that all of the predictions lie within $\pm 15 \%$. As the simulation under predicted the heat transfer, energy recovery was less, hence why the comparison was consistently less as shown by the trendline, which decribes a $-7 \%$ error. 


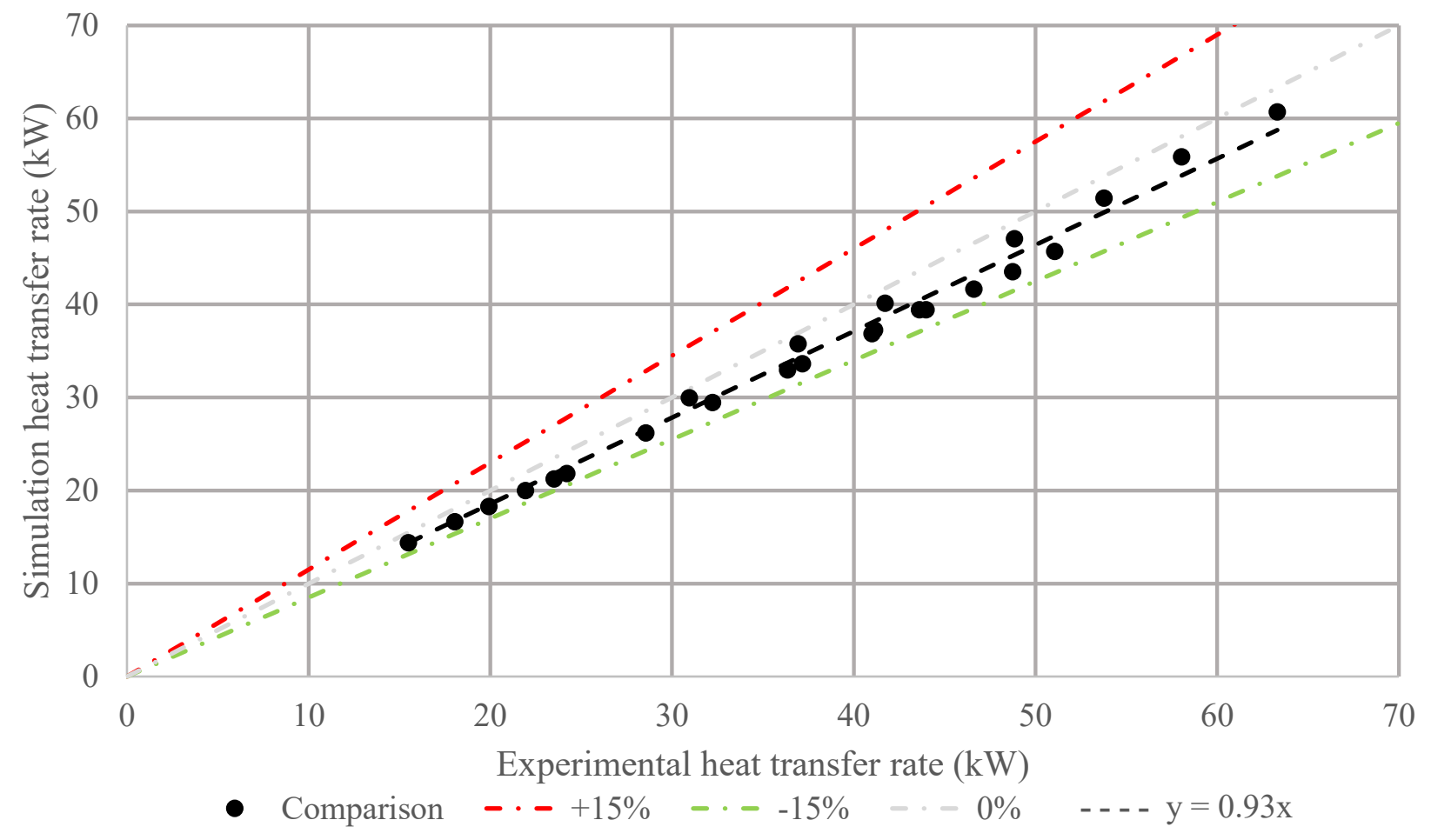

Figure 22: Comparison between Experimental and Simulated heat transfer rate.

\subsection{Conductance of the HPHE and Flow Rate}

To further characterise the HPHE, it was important to experimentally determine the conductance values and the effect of flow rate on the value of conductance. Figure 23 shows the conductance values, UA, plotted against mass flow rate, $\mathrm{kg} \mathrm{hr}^{-1}$. Equation 1 was used to determine the conductance. The values ranged between approximately $260-440 \mathrm{~W} \cdot \mathrm{K}^{-1}$ across the experiments. As the mass flow rate increases, the conductance values increased. This is expected as the overall heat transfer coefficient, $U$, is related to the heat transfer coefficient of forced convection, $h_{f c}$. As the mass flow rate increases, $h_{f c}$ increases as increased mass flow rate is a function of velocity. The HPHE studied has a bundle of tubes in a staggered arrangement with the exhaust gases passing cross-flow. As the velocity increases, the Reynolds number increases as shown by Equation 18, which increases the Nusselt number, as the available correlations are in the form of Equation 19, the heat transfer coefficient is determined from Equation 20 [33].

$$
\operatorname{Re}_{D}=\frac{U_{\max } \times D}{v}
$$

$R e_{D}$ is the Reynolds number associated with $\mathrm{D}$, dimensionless, $U_{\max }$ is the maximum velocity times time the free-flow velocity of the exhaust, $\mathrm{m} \cdot \mathrm{s}^{-1}, \mathrm{D}$ is the characteristic dimension, in this case, the outer diameter of the heat pipe, $\mathrm{m}, v$ is the kinematic viscosity of the fluid, $\mathrm{m}^{2} \cdot \mathrm{s}^{-1}$.

$$
N u_{D}=C \operatorname{Re}_{D}{ }^{x} \operatorname{Pr}^{0.36}\left(\frac{P r}{P r_{\text {sur }}}\right)^{0.25}
$$


$N u_{D}$ is the Nusselt number associated with the outer diameter of the heat pipe, dimensionless, $C$ is a correction factor determined empirically from test data, dimensionless, $x$ is the exponent of $R e_{D}$ determined using available empirical correlations, dimensionless, $\operatorname{Pr}$ is the Prandtl number, dimensionless, $P r_{\text {sur }}$ is Prandtl number determined at the heat pipe tube surface, dimensionless.

$$
h_{f c}=\frac{N u_{D} \times k}{D}
$$

$\mathrm{k}$ is the thermal conductivity of the fluid, $\mathrm{W} \cdot \mathrm{m}^{-1} \cdot \mathrm{K}^{-1}$.

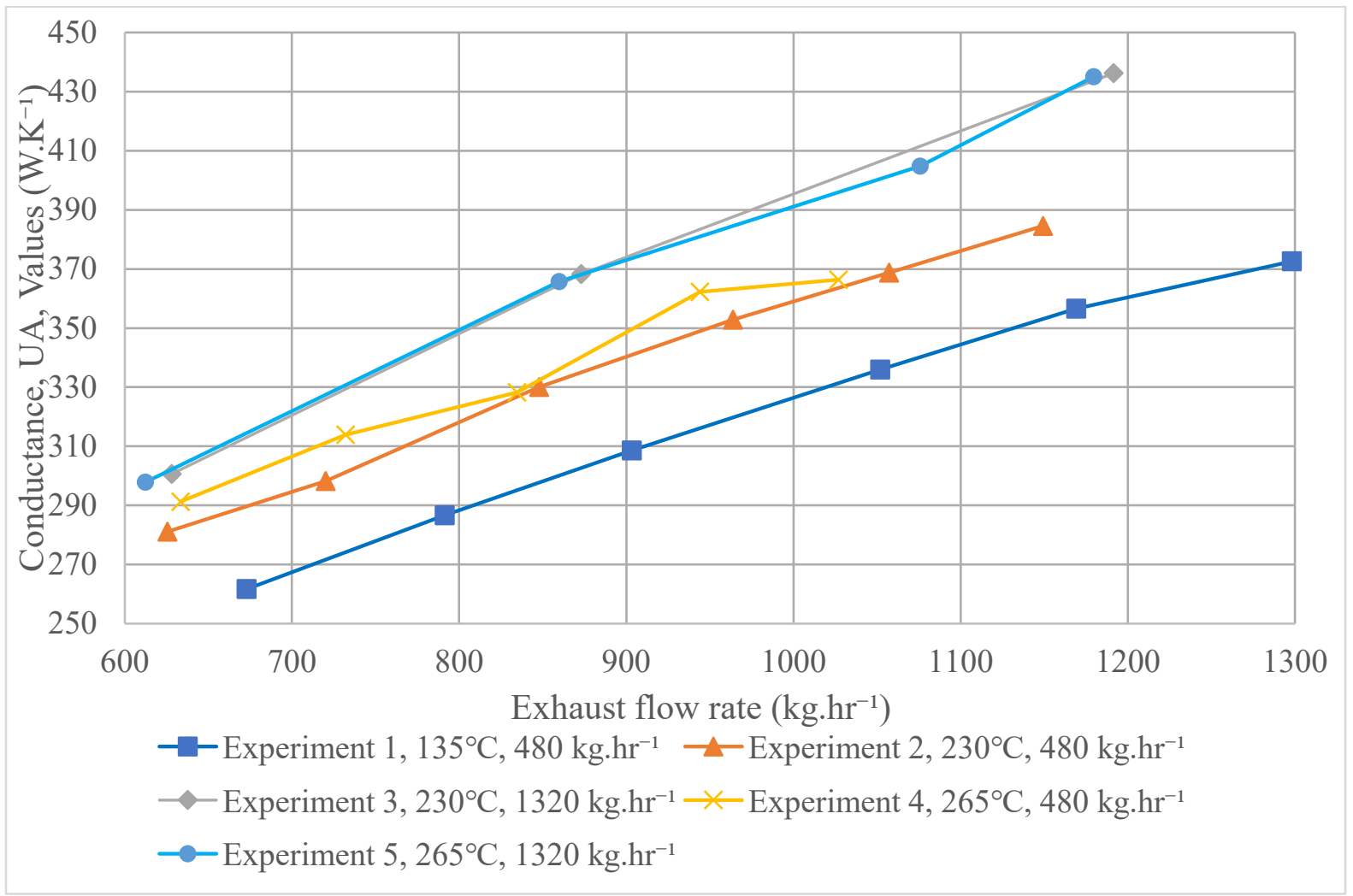

Figure 23: Graph showing the conductance, UA, values against flow rate of exhaust gases for each experiment.

\subsection{Optimum Operating Conditions and Limiting Factors}

Optimum operating conditions are seen with a higher temperature and mass flow rate. The heat pipes are capable of transferring energy provided, as seen by the increasing recovery in Figure 23 , but there are several limiting factors that will prevent and limit further energy transfer. The main limiting factor is attributable to the working fluid selected inside the heat pipe for two phase heat transfer. As the temperature increases, the pressure increases within the heat pipe as increased vapour phase is seen. The heat pipe material and thickness should be rated to take this pressure, also the liquid phase volume will decrease with increased vapour phase, which halts the effective operation of the heat pipe. The high temperature limit calculated for this $\mathrm{HPHE}$ was $290^{\circ} \mathrm{C}$. To prevent any failure on site only up to around $270{ }^{\circ} \mathrm{C}$ was tested. Another limiting factor is the heat transfer area of the heat pipes. This was overcome by creating multiple passes within the unit both in the evaporator and condenser sections to enhance the heat transfer coefficient. It can be seen from the experimental results that the exhaust outlet temperature was always higher than the water outlet temperature. This means there was 
unrecovered potential energy. However, due to thermodynamic characterisitics there is a lower heat transfer rate and therefore diminishing returns as the temperature difference gets less between the two outlet streams. This means that recovering more energy is increasing less economical to obtain as the heat exchanger size needs to larger to increase the heat transfer area. Many other limiting factors need taking into account on the design. A good review of heat transfer limitations have been published by Faghri [34]. Overall, the optimum conditions are based upon the design of the heat pipes and structural casing.

\subsection{Error Analysis}

Table 10 shows the energy recovery rate and uncertainty of the experimental results. Energy recovery rate, $\dot{Q}$, can be found using Equation 2. For this calculation the difference between the exhaust outlet and inlet temperatures has been used. To work out the uncertainty of the energy recovered $\left(S_{\dot{Q}}\right)$ reading Equation 21 was used [35].

$$
S_{\dot{Q}}=\dot{Q} \times \sqrt{\left(\frac{S_{\dot{m}}}{\dot{m}}\right)^{2}+\left(\frac{S_{\Delta T}}{\Delta T}\right)^{2}}
$$

where $S_{\Delta T}$ is the uncertainty associated with the difference in temperature, shown by Equation 22. $S_{\dot{m}}$ is the uncertainty associated with the mass flow rate, given by Equation 23. $S_{\dot{m}}$ has uncertainty associated with both volume flow rate and temperature as the ideal gas law, Equation 9, was used to determine the mass flow rate.

$$
\begin{gathered}
S_{\Delta T}=\sqrt{S_{T, \text { in }}{ }^{2}+S_{T, \text { out }}{ }^{2}} \\
S_{\dot{m}}=\sqrt{{S_{\dot{V}}{ }^{2}+S_{T}{ }^{2}}^{2}}
\end{gathered}
$$

\begin{tabular}{|c|c|c|c|c|c|}
\hline Simulation & Condition & $\begin{array}{c}\text { Av. Mass } \\
\text { Flow Rate } \\
\end{array}$ & $\begin{array}{c}\text { Energy Recovery } \\
\text { Rate, kW }\end{array}$ & $\begin{array}{c}\text { Uncertainty, } \pm x \\
k W\end{array}$ & Error, $\pm \mathbf{x} \%$ \\
\hline \multirow{6}{*}{1} & 1 & 673 & 15.5 & 0.9 & 5.5 \\
\hline & 2 & 791 & 18.0 & 1.0 & 5.6 \\
\hline & 3 & 903 & 19.9 & 1.1 & 5.6 \\
\hline & 4 & 1052 & 21.9 & 1.2 & 5.7 \\
\hline & 5 & 1169 & 23.5 & 1.3 & 5.7 \\
\hline & 6 & 1298 & 24.2 & 1.4 & 5.8 \\
\hline \multirow{6}{*}{2} & 1 & 625 & 28.6 & 1.5 & 5.2 \\
\hline & 2 & 720 & 32.2 & 1.7 & 5.2 \\
\hline & 3 & 848 & 37.2 & 1.9 & 5.2 \\
\hline & 4 & 964 & 41.0 & 2.1 & 5.2 \\
\hline & 5 & 1057 & 44.0 & 2.3 & 5.2 \\
\hline & 6 & 1149 & 46.6 & 2.4 & 5.2 \\
\hline \multirow{2}{*}{3} & 1 & 628 & 30.9 & 1.6 & 5.2 \\
\hline & 2 & 873 & 41.7 & 2.2 & 5.2 \\
\hline
\end{tabular}

Table 10: Energy recovery rate during each experimental condition with uncertainty values. 


\begin{tabular}{|c|c|c|c|c|c|}
\hline & 3 & 1192 & 53.8 & 2.8 & 5.2 \\
\hline \multirow{4}{*}{4} & 1 & 633 & 36.4 & 1.9 & 5.1 \\
\cline { 2 - 7 } & 2 & 732 & 41.1 & 2.1 & 5.1 \\
\cline { 2 - 6 } & 3 & 835 & 43.6 & 2.2 & 5.1 \\
\cline { 2 - 6 } & 4 & 944 & 48.7 & 2.5 & 5.2 \\
\hline \multirow{4}{*}{5} & 5 & 1027 & 51.1 & 2.6 & 5.2 \\
\cline { 2 - 6 } & 1 & 612 & 36.9 & 1.9 & 5.1 \\
\cline { 2 - 6 } & 2 & 860 & 48.8 & 2.5 & 5.1 \\
\cline { 2 - 6 } & 3 & 1076 & 58.0 & 3.0 & 5.1 \\
\hline
\end{tabular}

\section{Conclusion}

A novel multi-pass vertical heat pipe heat exchanger to recover heat from a ceramic kilns' exhaust gas has been installed on a lab scale kiln and experimentally analysed. Furthermore, a TRNSYS model has been developed to simulate experimental conditions with agreement accurate enough for engineering applications. The effects of temperature, exhaust flow rate and water temperature to the condenser section of the HPHE have been investigated. It was observed that the HPHE could obtain energy from exhaust gas temperatures approaching $270^{\circ} \mathrm{C}$, up to $1298 \mathrm{~kg} \cdot \mathrm{hr}^{-1}$ exhaust gas mass flow rate and $1320 \mathrm{~kg} \cdot \mathrm{hr}^{-1}$ water flow rate with energy recovery rates up to $63 \mathrm{~kW}$. The mass flow rate of the exhaust gas and water as well as temperature determined the conductance value of the heat exchanger through forced convection which determines the rate of heat recovery. As the mass flow rates of water and exhaust gases or temperature increased, the conductance of the HPHE increased. The experimental results comply with the simulated results with good agreement while understanding the limitations. Error analysis has shown good accuracy, less than $5.8 \%$ error, which is acceptable for engineering applications. Comparison between experimental and simulated energy recovery rates is also within $\pm 15 \%$ though initial temperature output values could be improved. The results presented in this paper validate the possibility of recovering energy from exhaust gases for a ceramic kiln. This experiment has concluded that HPHE can be an efficient method of recovering waste heat from CRK exhaust gases. This design of HPHE can be upscaled to an industrial scale and the energy content can be used to optimise process efficiencies or provide hot water, among other site-specific uses. ROI analysis of a theoretical installation has seen payback periods of 33 months for a full-scale installation creating hot water for utilisation within the facility. The experiment was set up to allow the introduction of water vapour or particulates into the exhaust stream. Further work is needed to fully characterise the effect of these on the HPHE performance. Furthermore, it would be beneficial to create and validate a dedicated HPHE component for use within the TRNSYS software.

\section{Acknowledgements}

The research presented in this paper has received funding from the European Union's H2020 programme Smartrec, under grant agreement number 723838.

\section{Declaration of Competing Interest}


None.

\section{References}

[1] Central Intelligence Agency. The World Factbook 2016-17. 2018.

[2] Jouhara H, Olabi AG. Editorial: Industrial waste heat recovery. Energy 2018;160:1-2. doi:10.1016/j.energy.2018.07.013.

[3] Agathokleous R, Panayiotou G, Aresti L, Argyrou MC, Georgiou GS, Jouhara H, et al. Waste Heat Recovery in the EU industry and proposed new technologies. Energy Procedia 2019;161:489-96. doi:10.1016/J.EGYPRO.2019.02.064.

[4] Solomon S, Plattner GK, Knutti R, Friedlingstein P. Irreversible climate change due to carbon dioxide emissions. Proc Natl Acad Sci U S A 2009;106:1704-9. doi:10.1073/pnas.0812721106.

[5] Zhang Z, Pan SY, Li H, Cai J, Olabi AG, Anthony EJ, et al. Recent advances in carbon dioxide utilization. Renew Sustain Energy Rev 2020;125:109799. doi:10.1016/j.rser.2020.109799.

[6] Brough D, Jouhara H. The aluminium industry: A review on state-of-the-art technologies, environmental impacts and possibilities for waste heat recovery. Int $\mathrm{J}$ Thermofluids 2020;1-2:100007. doi:10.1016/J.IJFT.2019.100007.

[7] Jouhara H, Khordehgah N, Almahmoud S, Delpech B, Chauhan A, Tassou SA. Waste heat recovery technologies and applications. Therm Sci Eng Prog 2018;6:268-89. doi:10.1016/J.TSEP.2018.04.017.

[8] Vrije Universiteit Brussel (VUB) - Institute for European Studies (IES). Industrial Value Chain. A Bridge Towards a Carbon Neutral Europe. 2018.

[9] Mezquita A, Boix J, Monfort E, Mallol G. Energy saving in ceramic tile kilns: Cooling gas heat recovery. Appl Therm Eng 2014;65:102-10. doi:10.1016/J.APPLTHERMALENG.2014.01.002.

[10] Ros-Dosdá T, Fullana-i-Palmer P, Mezquita A, Masoni P, Monfort E. How can the European ceramic tile industry meet the EU's low-carbon targets? A life cycle perspective. J Clean Prod 2018;199:554-64. doi:10.1016/J.JCLEPRO.2018.07.176.

[11] Agrafiotis C, Tsoutsos T. Energy saving technologies in the European ceramic sector: A systematic review. Appl Therm Eng 2001;21:1231-49. doi:10.1016/S13594311(01)00006-0.

[12] Ferrer S, Mezquita A, Aguilella VM, Monfort E. Beyond the energy balance: Exergy analysis of an industrial roller kiln firing porcelain tiles. Appl Therm Eng 2019;150:1002-15. doi:10.1016/J.APPLTHERMALENG.2019.01.052.

[13] Agnani E, Cavazzuti M, Corticelli MA. Optimization of recuperative burners for industrial kilns through CFD simulation OPTIMIZATION OF RECUPERATIVE BURNERS FOR 2015.

[14] Almahmoud S, Jouhara H. Experimental and theoretical investigation on a radiative flat heat pipe heat exchanger. Energy 2019;174:972-84. doi:10.1016/j.energy.2019.03.027.

[15] Jouhara H, Chauhan A, Nannou T, Almahmoud S, Delpech B, Wrobel LC. Heat pipe based systems - Advances and applications. Energy 2017;128:729-54. doi:10.1016/j.energy.2017.04.028.

[16] Pal E, Kumar I, Joshi JB, Maheshwari NK. CFD simulations of shell-side flow in a shelland-tube type heat exchanger with and without baffles. Chem Eng Sci 2016;143:31440. doi:10.1016/j.ces.2016.01.011.

[17] Srimuang W, Amatachaya P. A review of the applications of heat pipe heat exchangers for heat recovery. Renew Sustain Energy Rev 2012;16:4303-15. doi:10.1016/j.rser.2012.03.030.

[18] Alammar AA, Al-Dadah RK, Mahmoud SM. Numerical investigation of effect of fill 
ratio and inclination angle on a thermosiphon heat pipe thermal performance. Appl Therm Eng 2016;108:1055-65. doi:10.1016/j.applthermaleng.2016.07.163.

[19] Pishvar M, Saffar Avval M, Mansoori Z, Amirkhosravi M. Three dimensional heat transfer modeling of gas-solid flow in a pipe under various inclination angles. Powder Technol 2014;262:223-32. doi:10.1016/j.powtec.2014.04.075.

[20] Alizadehdakhel A, Rahimi M, Alsairafi AA. CFD modeling of flow and heat transfer in a thermosyphon. Int Commun Heat Mass Transf 2010;37:312-8. doi:10.1016/j.icheatmasstransfer.2009.09.002.

[21] Jouhara H, Fadhl B, Wrobel LC. Three-dimensional CFD simulation of geyser boiling in a two-phase closed thermosyphon. Int J Hydrogen Energy 2016. doi:10.1016/j.ijhydene.2016.02.038.

[22] Fadhl B, Wrobel LC, Jouhara H. CFD modelling of a two-phase closed thermosyphon charged with R134a and R404a. Appl Therm Eng 2015;78:482-90. doi:10.1016/j.applthermaleng.2014.12.062.

[23] Egilegor B, Jouhara H, Zuazua J, Al-Mansour F, Plesnik K, Montorsi L, et al. ETEKINA: Analysis of the potential for waste heat recovery in three sectors: aluminium low pressure die casting, steel sector and ceramic tiles manufacturing sector. Int $\mathrm{J}$ Thermofluids 2019:100002. doi:https://doi.org/10.1016/j.ijft.2019.100002.

[24] Ramos J, Chong A, Jouhara H. Experimental and numerical investigation of a cross flow air-to-water heat pipe-based heat exchanger used in waste heat recovery. Int J Heat Mass Transf 2016;102:1267-81. doi:10.1016/j.ijheatmasstransfer.2016.06.100.

[25] Mroue H, Ramos JB, Wrobel LC, Jouhara H. Experimental and numerical investigation of an air-to-water heat pipe-based heat exchanger. Appl Therm Eng 2015;78:339-50. doi:10.1016/j.applthermaleng.2015.01.005.

[26] Mroue H, Ramos JB, Wrobel LC, Jouhara H. Performance evaluation of a multi-pass air-to-water thermosyphon-based heat exchanger. Energy 2017;139:1243-60. doi:10.1016/j.energy.2017.04.111.

[27] Delpech B, Milani M, Montorsi L, Boscardin D, Chauhan A, Almahmoud S, et al. Energy efficiency enhancement and waste heat recovery in industrial processes by means of the heat pipe technology: Case of the ceramic industry. Energy 2018;158:65665. doi:10.1016/j.energy.2018.06.041.

[28] Delpech B, Axcell B, Jouhara H. Experimental investigation of a radiative heat pipe for waste heat recovery in a ceramics kiln. Energy 2018;170:636-51. doi:10.1016/j.energy.2018.12.133.

[29] Khordehgah N, Guichet V, Lester SP, Jouhara H. Computational study and experimental validation of a solar photovoltaics and thermal technology. Renew Energy 2019;143:1348-56. doi:10.1016/j.renene.2019.05.108.

[30] Massaguer E, Massaguer A, Montoro L, Gonzalez JR. Development and validation of a new TRNSYS type for the simulation of thermoelectric generators. Appl Energy 2014;134:65-74. doi:10.1016/J.APENERGY.2014.08.010.

[31] Çengel Y. Heat Transfer: A Practical Approach. Second. Mcgraw-Hill (Tx); 2002.

[32] Sandbag. Carbon Price Viewer n.d. https://sandbag.org.uk/carbon-price-viewer/ (accessed February 3, 2020).

[33] Kreith F, Manglik RM, Bohn MS. Principles of Heat Transfer. 7th ed. Stamford: Cengage Learning, Inc; 2011.

[34] Faghri A. Heat Pipes: Review, Opportunities and Challenges. Front Heat Pipes 2014;5. doi:10.5098/fhp.5.1.

[35] Taylor JR. An Introduction to Error Analysis: The Study of Uncertainties in Physical Measurements. Second. University Science Books, U.S.; 1997. 